\title{
Review Article \\ Critical Velocity and Backlayering Conditions in Rail Tunnel Fires: State-of-the-Art Review
}

\author{
Razieh Khaksari Haddad $\mathbb{D}^{1},{ }^{1}$ Cristian Maluk, ${ }^{2}$ Eslam Reda, ${ }^{1}$ and Zambri Harun ${ }^{1}{ }^{1}$ \\ ${ }^{1}$ Faculty of Engineering and Built Environment, The National University of Malaysia, 43600 Bangi, Malaysia \\ ${ }^{2}$ School of Civil Engineering, The University of Queensland, St Lucia, QLD 4072, Australia \\ Correspondence should be addressed to Zambri Harun; zambri@ukm.edu.my
}

Received 20 November 2018; Revised 17 April 2019; Accepted 28 April 2019; Published 28 May 2019

Academic Editor: Benjamin Shaw

Copyright (C) 2019 Razieh Khaksari Haddad et al. This is an open access article distributed under the Creative Commons Attribution License, which permits unrestricted use, distribution, and reproduction in any medium, provided the original work is properly cited.

The use of interurban and urban trains has become the preferred choice for millions of daily commuters around the world. Despite the huge public investment for train technology and mayor rail infrastructure (e.g., tunnels), train safety is still a subject of concern. The work described herein reviews the state of the art on research related to critical velocity and backlayering conditions in tunnel fires. The review on backlayering conditions includes the effect of blockages, inclination, and the location of the fire source. The review herein focuses on experimental and theoretical research, although it excludes research studies using numerical modeling. Many studies have used scaled tunnel structures for experimental testing; nevertheless, there are various scaling challenges associated with these studies. For example, very little work has been done on flame length, fire source location, and the effect of more than one blockage, and how results on scaled experiments represent the behaviour at real-scale. The review sheds light on the current hazards associated with fires in rail tunnels.

\section{Introduction}

Tunnel fire research is one of the most challenging areas for fire researchers. Despite strict regulations and sophisticated assessment methods, accidents continue to occur A range of fire loads expected from different trains and tunnel configurations add to the complexity of the research. Because of the tunnels' special structure, the movements of combustion flows inside them make it much different with fires in open spaces. These usually cross-passage transport routes should be free of smokes and combustion products and, therefore, provide safe evacuation paths for passengers. Special considerations should be taken into account to enhance safety in the events of fire. In recent years, fire safety engineering has received more attention among researchers due to the increasing number of disastrous tunnel fires and the increasing number of tunnels construction. One important question in the design of tunnel structures among tunnel specialists and other parties considered is the type of ventilation which could maintain smoke-free conditions. Designers usually use different types of ventilation including the longitudinal, natural, and transverse ventilation; these are selected according to the installation and operational costs and the desired safety level. When a fire breaks out in a tunnel, it spreads in the downstream and upstream directions. The smoke flow which spreads in the upstream side is named backlayering and a minimum ventilation velocity which could eliminate the smokes is called the critical velocity. These two parameters have been investigated widely in recent years. There are many researchers who investigate the critical velocity and backlayering experimentally; however, this parameter has also been conducted numerically such as Khaksari's study [1] which was on a computational fluid dynamic (CFD) simulation of an unexpected fire occurring in a one-way mass-railway transit (MRT) tunnel. The researchers investigate the effect of various forced ventilation velocities on the temperature distribution and the stratification of the pollutants to estimate the critical velocity.

In this paper, a review of the efforts of different researchers in the field of the tunnel fire research is presented in order to investigate the critical velocity, backlayering characteristics, and the impact of blockage, slope, and fire source location on them. 


\section{Critical Velocity}

One of the basic scientific problems, when a fire occurs in a tunnel, is the specification of the longitudinal ventilation velocity necessary to prevent upstream movement of combustion products. So far, the value of the critical velocity for various tunnels has been obtained mainly from sets of equations derived by applying the Froude number conservation, combined with experimental data [2-8]. The Froud number is the ratio of inertia forces to gravitational force. Extensive works have also been reported in the literature to characterize the critical ventilation velocity. The Froude number preservation technique was applied in Thomas [9] to study the effect of ventilation velocity on fire flow in underground tunnels. Thomas [9] investigated fire plume in some full-scale and small-scale models and presented the general idea of the critical velocity in tunnel flow assuming the Froude number equals to unity. In this study, the critical velocity is defined as the longitudinal velocity needed to eliminate the backlayering of hot gases. He derived the following semiempirical equation for the critical velocity:

$$
U_{C}=k\left(\frac{g Q^{\prime}}{\rho_{0} C_{P} T}\right)^{1 / 3},
$$

where $U_{C}$ is the critical velocity, which can eliminate the smoke flow, $g$ is the acceleration due to gravity, $Q^{\prime}$ is the convective heat release rate (HRR) per unit width of the tunnel, $\rho_{0}$ is the specific heat capacity of air, $k$ is a constant (Thomas [9] found that $k=1$, giving an adequate result with test data), and $T$ is smoke temperature. Equation (1) can apply for rectangular cross-section.

Thomas's study [9], a pioneer researcher in the critical velocity, has been revisited to a more advanced perspective by many other researchers. Focusing on different parameters that can influence the critical velocity, including the tunnel geometry, tunnel slope, or plume flow, is the frequent factor in these studies. Hinkley [10] also studied the flow of hot gases and smoke flow in a different situation compared with Thomas experiment (one-end closed corridor in a shopping mall) and gave a theoretical background of this subject. A formula was derived for calculating the rate of spread of a layer of hot gases beneath the ceiling and the depth of the layer. Hinkley [10] used the same theory as Thomas [9] and came up with a similar cube-root relationship between the velocity of hot gases spreading along the shopping mall ceiling and heat release rate; i.e., he assumed that the value of smoke velocity is equal to the ventilation velocity:

$$
V=K^{\prime}\left(\frac{g Q T}{\rho_{0} C_{P} T_{a}^{2} W}\right)^{1 / 3},
$$

where $W$ is the width of the tunnel, $T_{a}$ is ambient temperature, and $K^{\prime}$ from experimental result of the movement of the hot smoke flow in relatively short corridors without forced ventilation was found to be 0.8 . Hinkley [10] established a formula for the depth of the hot smoke layer beneath the ceiling. He found out that the depth of the layer is approximately proportional to the perimeter of the fire source and inversely proportional to the velocity of the layer and the width of the mall. The critical velocity calculated from (2) has an agreement with the experimental result of a study carried out in Japan (Report of fire test, 1966) on the smoke logging of an underground car park.

The study of the critical velocity was continued by Heselden [8] in which in turn a formula was driven based on Hinkley's theory [10] for calculating the critical ventilation velocity. In addition to the basic formula for calculating the critical velocity, he estimated heat release rates for cars (5MW) and Heavy Good Vehicles (20MW), which still constitute the basis for many design guidelines. His formula included constants extracted from a limited set of data for large scale tests in Glasgow. The critical velocity was defined as follows:

$$
U_{C}=C K\left(\frac{g Q T}{\rho_{0} C_{P} T_{a}^{2} W}\right)^{1 / 3}
$$

where both $C$ and $K$ are constants obtained from experiments in a disused rail tunnel. The critical ventilation velocity results in [8-10] were widely used as the basis for specifying characteristics of the critical velocities in road tunnels and have essential effect on our knowledge in tunnel fire engineering. These models suggested that the critical ventilation velocity varies with the cube root of the heat release per unit width of the tunnel. It should be considered that this conclusion was supported by dimensional analysis and some experimental results $[8,10]$. However, when the size of the flames is significantly smaller than the height of the tunnel and flame does not impinge the ceiling, the dimensional equations proposed by Heselen [8] and Hinkley [10] are only valid. The most widely used correlations to predict the critical ventilation velocity are Heselden's results [8]. For instance, a simple relationship was derived from semiempirical equations based on Froude number modeling and Heselden's theory by Danziger and Kennedy ([5]). Danziger and Kennedy collaborated with the US Department of Transport Subway Environment Simulation Program in 1982 and a value of the critical velocity for a simple tunnel model was derived. This model was based on the relationship between the temperature increase of smoke and the convective heat release rate. It should be mentioned that although the Danziger and Kennedy model varies with one-third power of HRR as Thomas and Hinkley reported, it has a grade correction factor for slopping tunnel. This model was also used in a computer model called the Subway Environmental Simulation (SES) (Parsons, Brinckerhoff). The previously established relationships, which assumed critical velocities were related to the cube root of heat release for all values of the heat release rate, are not accurate when fire flame impinges the ceiling. Therefore, this issue should be considered separately since very large rates of heat release are produced by vehicle fires. Oka and Atkinson [11] carried out further developed important work using dimensional analysis in order to solve this problem. The objective of their work was precisely and systematically measuring critical velocities for a model tunnel fire and testing the scaling procedures used. Oka and Atkinson [11] used the tunnel height as the characteristic length and derived a new simple 
formula to predict the critical velocity, which can be applied to small and large fires. They concluded that, for low rates of heat release, the critical velocity does vary as the cube root of the heat release rate. At higher rates of heat release rate, the dependence on the heat release rate falls off rapidly until it becomes independent of HRR. In other words, a limit value, called supercritical velocity, was defined when HRR increases. Equation (1) from Thomas's considerations is obviously unable to represent such an asymptotic behavior. The dimensionless critical velocity and HRR were defined, respectively, as follows:

$$
\begin{aligned}
Q^{*} & =\frac{Q}{\rho_{0} C_{P} T_{a} g^{1 / 2} H^{5 / 2}}, \\
U_{C}^{*} & =\frac{U_{C}}{\sqrt{g H}} .
\end{aligned}
$$

Oka and Atkinson [11] suggested the following replacement for (1) presented by Thomas:

$$
U_{C}^{*}= \begin{cases}0.35(0.124)^{-1 / 3}\left(Q^{*}\right)^{1 / 3} & \text { for } Q^{*} \leq 0.124 \\ 0.35 & \text { for } Q^{*}>0.124\end{cases}
$$

Then, they adjusted (6) for different burner's size, shape, and location as well as situations with a blockage. Grant et al. [12] performed research review related to fires in tunnels and noted that current practice in longitudinal ventilation still showed lack of basic fundamental understandings of the interactions between buoyancy-driven smoke and forced ventilation, the effect of tunnel geometry, and the validity of derivation of small-scale results to large scales. Despite small scale tunnels, they manage to conclude that using hydraulic diameter may provide a meaningful quantitative relation to accounting for cross-section blockage ratio and tunnel width variations.

The studies by [5,9-11] were based on one single tunnel geometry, and the tunnel height has been used as the characteristic length in the dimensionless analysis. For example, Oka and Atkinson used the tunnel height as characteristics length so (6) cannot correspond to the experimental results from various cross-sectional tunnel shapes into a single form. Therefore, the effect of tunnel geometry on the critical ventilation velocity remains unclear and needs to be examined. Consequently, this problem led to the issues of the new scaling techniques in tunnel fires. Wu and Bakar [13] carried out a series of experimental tests in five model tunnels having the same height but different cross-sectional geometries. Although the changes of the critical velocity against HRR can be divided into two regimes in Wu and Bakar's research, the new dimensionless critical ventilation velocity, $U_{C}^{*}$, and new dimensionless heat release, $Q^{*}$, are defined as

$$
\begin{aligned}
Q^{*} & =\frac{Q}{\rho_{0} C_{P} T_{a} g^{1 / 2} \bar{H}^{5 / 2}}, \\
U_{C}^{*} & =\frac{U_{C}}{\sqrt{g \bar{H}}} .
\end{aligned}
$$

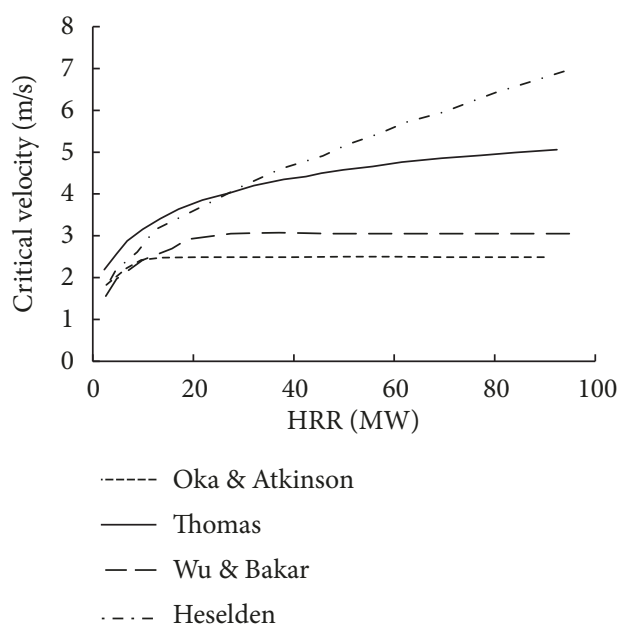

FIgURE 1: The comparison between critical velocities as a function of HRR.

A simple one-dimensional correlation was proposed in [13] to predict the critical ventilation velocity for tunnels according to their experimental results. The suggested equations are

$$
U_{C}^{*}= \begin{cases}0.4(0.2)^{-1 / 3}\left(Q^{*}\right)^{1 / 3} & \text { for } Q^{*} \leq 0.2 \\ 0.4 & \text { for } Q^{*}>0.2\end{cases}
$$

As shown in [13], there are two differences between Oka and Atkinson's study [11] and Wu and Bakar's study [13]. The tunnel hydraulic height (tunnel hydraulic height here means hydraulic diameter) was used as the characteristic length in $\mathrm{Wu}$ and Bakar's research while Oka and Atkinson used the tunnel height instead. At low HRRs, critical velocity changes were related to the one-third power of the HRR in both studies $[11,13]$; however, the amount of supercritical velocity at higher HRRs is 0.4 in [13] which is 0.35 in [11]. In Figure 1, critical velocities based on (1), (3), (6), and (8) are presented as a function of HRR. It is assumed that all correlations are according to convective HRR, which is a factor of 0.7 ( $30 \%$ radiation heat transfer). According to this figure, the critical velocity calculated by Oka'model is approximately close to Wu's relationship. However, the equation suggested by Thomas overestimates the critical velocity. Moreover, Heselden's model shape is different from others.

The geometry of the tunnel is a significant parameter influencing the development of a fire. The height plays an important role because it influences the speed of going up smoke. In addition, the tunnel width that affects the ceiling area and consequently the heat transfer and smoke velocity should be considered. Therefore, the formula presented by $\mathrm{Wu}$ and Bakar [13] was corrected in Lee and Ryou study [14] through determining the critical velocity considering aspect ratio, which is height/width for a tunnel of rectangular cross section. In their study, reduced-scale experiments were carried out under the Froude scaling modeling using ethanol pool fire and the critical velocity was investigated with various aspect ratios $(0.5,0.667,1.0,1.5$, and 2.0$)$ of the tunnel cross section in tunnel fires. Though the smoke movement may 
follow the different trend in tunnels with the same hydraulic diameter and different aspect ratio, this study uses new dimensionless critical velocity $\left(U_{C}^{*}\right)$ and dimensionless HRR $\left(Q^{*}\right)$ considering aspect ratio of the tunnel.

$$
\begin{aligned}
& Q^{*}=\frac{Q}{\rho_{0} C_{P} T_{a} g^{1 / 2} \bar{H}^{5 / 2} A_{S}^{1 / 2}}, \\
& U_{C}^{*}=\frac{U_{C}}{A_{S}^{0.2} \sqrt{g \bar{H}}} .
\end{aligned}
$$

Lee and Ryou [14] defined a new dimensionless critical ventilation velocity $U_{C}^{*}$, and a new dimensionless heat release rate, $Q^{*}$. The suggested equation based on a simple onedimensional correlation to predict the new dimensionless critical velocity for tunnels is

$$
U_{C}^{*}=0.73 Q^{* 1 / 3} \text {. }
$$

In this study, the range of the suggested equation is restricted to $Q^{\prime} \leqslant 0.2$. Therefore, further work must be investigated to predict the critical velocity in large fires. Lee and Ryou concluded that the formulae proposed by $\mathrm{Wu}$ and Bakar should not be used for tunnels that have the same hydraulic tunnel height but different aspect ratios. It has been also compared with other reduced scale experiments and fullscale experiments. It shows a good agreement between their results and others of small scale experiments. In order to describe the behavior of the fire gases spreading in opposite direction to a fresh air current induced by tunnel ventilation, a new theoretical model of a tunnel fire has also been proposed [15]. In particular, this model yields an analytic formula for estimating the critical ventilation velocity, which is required to prevent backlayering. In Kunsch's model [15], sideways deflection of the plume due to the momentum of the fresh-air current was neglected, which was strictly valid for tunnels with square cross sections only. So, it needed further analysis for elliptic cross sections. The model has been validated by comparison with most large-scale experiments in an instrumented gallery for a wide range of fire HRRs. In this model, a limit value (supercritical velocity) is also reached for high values of fire HRR.

Vauquelin and Telle [16] carried out an experimental study on a reduced scale tunnel model. The main objectives of this test were (1) to get a description of the flow patterns which appear for such a configuration and (2) to quantify the longitudinal air flow induced into the tunnel and to get a suitable definition of the confinement velocity, the minimum value of the longitudinal ventilation velocity required to stabilize and control the smoke layer downstream of the vent. The reason for using such velocity was the confinement of a fire plume between two exhaust vents in a tunnel and, at the same time, top reserve certain stratification. A comparison between experiments performed by Vauquelin and Thomas's and Oka's research shows that the confinement velocity for a certain HRR is lower than the critical velocity proposed by Thomas and Oka although its progress is approximately the same as the one presented by Thomas for the critical velocity. This is shown in Figure 2.

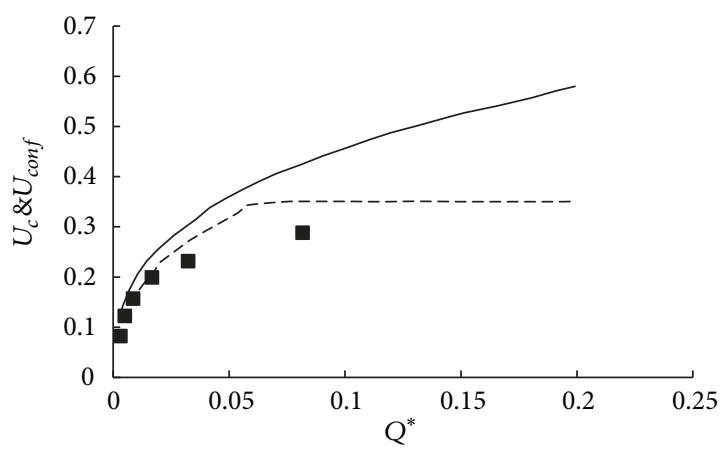

$$
\begin{aligned}
& \text { - } \mathrm{U}_{\text {conf }}-\text { Vauqueline, } 2005 \\
& ---\cdot \mathrm{U}_{\mathrm{c}}-\text { Oka, } 1995 \\
& -\mathrm{U}_{\mathrm{c}}-\text { Thomas, } 1968
\end{aligned}
$$

FIGURE 2: The comparison between the critical velocity and the confinement velocity.

Although limited research has been performed on the confinement velocity and the backlayering length, further investigations are needed for higher values of the fire HRR, and it is important to note that the confinement velocity defined in this paper was only related to the specific ventilation configuration tested (only two vents activated, one on each side of the fire source).

The influence of tunnel width $(W)$ on the critical velocity (for a given tunnel height $H$ ) was also studied by Vauquelin and $\mathrm{Wu}$ [17] experimentally on scale models. They found that an increase in tunnel width caused bigger critical velocities for small aspect ratios (less than unity). Although the trend of the critical velocity for aspect ratios greater than unity was different with Thomas's theory [9], i.e., $\left(U_{C} \sim W^{-1 / 3}\right)$, as the decrease of $U_{C}$ with $W$ was overestimated in Thomas's theory. Also, high values of HRR were explored by CFD calculations to study the influence of it on smoke plume spreading and, then, on the critical velocity [17]. Vauquelin [18] then continued his study by presenting experimental investigations carried out on an isothermal reduced scale tunnel model. His study focused on fire-induced smoke control by longitudinal and transverse ventilation systems. The principle of Vauquelin's experimental model was reproducing the mixed convection process (duality between inertial and buoyant forces) with accuracy. Experiments were carried out to study the evolution of the critical velocity as a function of several basic parameters: fire HRR, tunnel slope, tunnel height, and tunnel width. For the transverse control, basic experiments were carried out for a two vents system in order to estimate the extraction flow rate required for a given HRR.

Continuing research on the critical velocity, Roh et al. [19] performed the 1:20 reduced-scale experiments to investigate the change of burning rate and HRR due to the longitudinal ventilation velocity. In this case, he investigated pool fire, using three different types of fuel: methanol, n-heptane, and acetone. Pool fire is the burning of flammable liquid hydrocarbon fuel above a horizontal vessel under conditions of zero or very low initial momentum. In Roh's research for 
methanol pool fire [19], the increase in ventilation velocity reduces the burning rate. On the contrary, for acetone and nheptane pool fires, the increase in ventilation velocity leads to the enhanced burning rate of fuels. In his experiments also, the critical velocity showed a regular pattern to HRR. The following relationship (11) was obtained between fire convective HRR per tunnel unit width and the critical velocity. It should be highlighted that the fire sizes used in the present work were relatively small.

$$
U_{C}=\frac{-0.000845+8.1661 Q^{\prime}}{1+2.094 Q^{\prime}-0.021 Q^{\prime 2}} .
$$

It should be mentioned that the value of nondimensional critical velocity $\left(U_{C}^{*}\right)$ in Roh et al. study was more than nondimensional critical velocity presented by $\mathrm{Wu}$ and Bakar [13]. Experimental tests and theoretical analyses were conducted by $\mathrm{Li}$ et al. [20] to investigate the critical velocity together with the backlayering length in tunnel fires. They measured backlayering length by measurement of the gas temperature. In addition, the critical velocity was obtained by extrapolation of the backlayering length curve. They proposed a correlation between the dimensionless critical velocity and the dimensionless HRR and used tunnel height as the characteristic length. They proposed a simple onedimensional correlation to predict the critical ventilation velocity for tunnels according to their experimental results. The suggested equations are

$$
U_{C}^{*}= \begin{cases}U_{C}^{*}=0.81\left(Q^{*}\right)^{1 / 3} & \text { for } Q^{*} \leq 0.15 \\ U_{C}^{*}=0.43 & \text { for } Q^{*}>0.15 .\end{cases}
$$

The critical Froude number $\left(F r_{c}\right)$ and the critical Richardson number $\left(R i_{c}\right)$ were also calculated based on the fully mixed assumption. The Richardson number expresses the ratio of the buoyancy term to the flow shear term. Both the critical Froude number and the critical Richardson number were nearly constants for dimensionless HRRs less than 0.15 , but they were obviously at a higher level as the dimensionless heat release exceeds 0.15 [20].

$$
\begin{aligned}
& F r_{c}= \begin{cases}1.15 & \text { if } Q^{*} \leq 0.15 \\
1.15+3.7\left(Q^{*}-0.15\right) & \text { for } Q^{*}>0.15,\end{cases} \\
& R i_{c}= \begin{cases}1.15+2.35 Q^{*} & \text { if } Q^{*} \leq 0.15 \\
1.5+8.5\left(Q^{*}-0.15\right) & \text { for } Q^{*}>0.15 .\end{cases}
\end{aligned}
$$

Li's results [20] were evaluated with results from the largescale tests and found good agreement between model-scale tests and these large-scale tests. The predicted critical velocity proposed by Oka and Atkinson [11] and the equation proposed by Wu and Bakar [13] were lower than the experimental data of the critical velocity presented in this study, especially for a dimensionless HRR below 0.15 [20]. This is shown in Figure 3.

Recently, Li and Ingason [21] examined the influence of cross section of the tunnel on the critical velocity. They

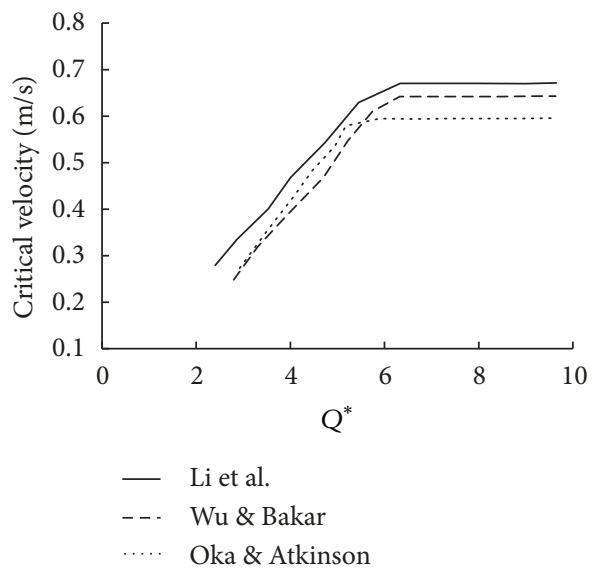

FIGURE 3: The comparison between the critical velocities presented in $\mathrm{Li} 2010$ [20].

analyzed the previous models for the critical velocity based on the effect of tunnel cross section and concluded that Oka and Atkinson's model underestimates the critical velocities while Wu and Bakar's model overestimates the effect of tunnel width on critical velocity for all sizes of fires. The results of this study show that the increase in both tunnel width and height results in a decrease in the critical velocities for small fires. However, the increasing of the tunnel height causes a significant increase in the critical velocities for large fires. Finally, a new systematic model was proposed to calculate the critical velocity as follows:

$$
U_{C}^{*}= \begin{cases}0.81 \beta^{-1 / 12}\left(Q^{*}\right)^{1 / 3} & \text { for } Q^{*} \leqslant 0.15 \beta^{-1 / 4} \\ 0.43 & \text { for } Q^{*}>0.15 \beta^{-1 / 4},\end{cases}
$$

where $\beta=W / H$. As the critical Froud number of 4.5 was widely used to calculate the critical velocity in a ventilated tunnel, Li and Ingason [22] studied the critical Froud number, its effectiveness, and original sources of the critical Froude model. They found out that using the critical Froud number of 4.5 leads to lower critical velocities for large fire size, which is not conservative. According to $\mathrm{Li}$ and Ingason investigation, this failure is due to the lack of consideration tunnel aspect ratio and tunnel geometry when a constant Froud number is taken into account. So the critical Froude number is not only not a constant but also influenced by both the heat release rate and tunnel aspect ratio. It can be concluded that although researchers proposed various equations to calculate the critical velocity, this parameter is changed by one-third power of HRR for low rates of heat release and at higher rates of heat release it is independent of HRR.

\section{Backlayering}

As mentioned in the Introduction, the backlayering length is defined as the length of the reversed smoke flow upstream of the fire when the ventilation velocity is lower than that of the critical velocity, as Figure 4 shows. One of the most 


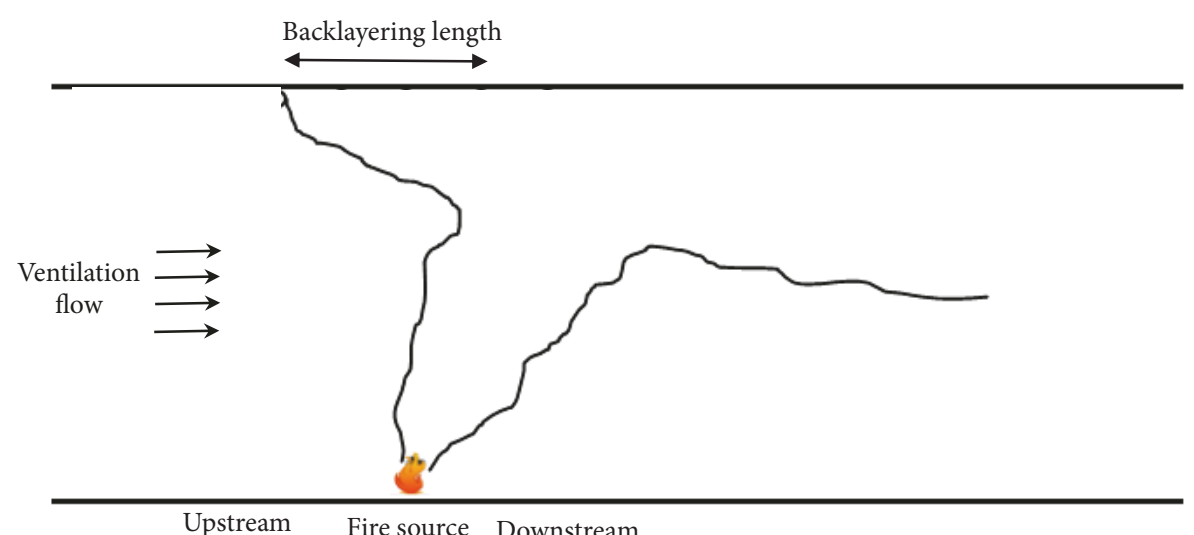

FIGURE 4: Backlayering length in tunnel fire under the longitudinal ventilation.

important questions in the design of the ventilation system of tunnels is the longitudinal ventilation velocity in comparison with the critical value, i.e., how far could the smokes and hot gases travel upstream from the fire source. So, it is essential to grasp the characteristics of the backlayering thermal fumes in the case of a tunnel fire. Despite increasing interests in the research into the backlayering characteristics in recent years, there has been a lack of studies on the critical velocity and its relationship with backlayering distance. However, underground stations where diesel-powered locomotives frequently stop and pass in them are also investigated in the situation where the mechanical and fire consultants are present such as Harun's study [23]. The smokes flow around the building was simulated numerically by using Star-CCM ${ }^{+}$ [23]. They estimated enough escape time for occupants to evacuate the building based on the ventilation condition in numerical simulation.

A theoretical analysis between the hot smoke flow and the flow which spreads in the upstream of the fire of a longitudinally ventilated tunnel fire was established by Thomas [24]. Thomas indicated that only if the velocity head of the inlet flow $U^{2} / 2 g$ (the inertial force of ventilation) is comparable to or greater than the differential pressure head due to chimney effect $H \Delta T_{c, \max } / T$ (the bouyancy of hot gases), the hot gases are expected not to flow downstream; here, $\Delta T_{c, \text { max }}$ is the maximum temperature downstream, $H$ is the height of tunnel, and $T$ is the absolute temperature of the hot gases. He suggested that the ratio of backlayering length to tunnel height $\left(L_{b} / H\right)$ would be a function of the ratio of $V^{2} / 2 g$ to $d \Delta T_{c, \text { max }}$. This ratio is also the Froude number. $\mathrm{He}$ also has initially proposed a dimensionless relation to estimate the smoke backlayering flow length as follows:

$$
L_{b}^{*}=\frac{L_{b}}{H} \propto \frac{g H Q}{\rho_{0} C_{P} T V^{3} A} ;
$$

in fact, as $A=H W,(15)$ can be rewritten as

$$
L_{b}^{*}=\frac{L_{b}}{H} \propto \frac{g Q}{\rho_{0} C_{P} T V^{3} W},
$$

where $L_{b}$ is the backlayering length, $\rho_{0}$ is the ambient density, $C_{P}$ is the specific heat, $T_{a}$ is the ambient temperature, $V$ is the ventilation velocity, and $H$ is the height of the tunnel. It can be concluded from (16) that the main specifications influencing the backlayering length are HRR, tunnel height and width, and longitudinal velocity. Since the equation proposed by Thomas was not followed by experimental results, it needs more investigation. However, the equation proposed by Thomas can be used to estimate the critical velocity just for smaller values of heat release rate, i.e., when $L_{b} / H=0$. The equation proposed by Thomas [24] was based on the analyzing of the Froude number. Another frequently used equation was the one that Vantelon [25] presented. He carried out a set of small-scale experiments and studied fire-induced smoke layer characteristics in a tunnel and a particular station of the Paris Metro with a ventilation system. In his experiment, a $1.5 \mathrm{~m}$ long semicircular pipe with $0.15 \mathrm{~m}$ radius was used and two approaches were investigated. Firstly, the length of the reverse layer and the effects of ventilation speed and HRR on it were considered. An equation for the dimensionless backlayering distance (18) based on modified Richardson number was developed (17) [25].

$$
R i^{\prime}=\left[\frac{g Q}{\rho_{0} C_{P} T_{a} V^{3} H}\right],
$$

or

$$
\frac{L_{b}}{H}=\left(R i^{\prime}\right)^{0.3}
$$

This derived formula is in agreement with the equation presented in Thomas's study [24] who predicted that the critical velocity has a correlation with $H R R$ to the $1 / 3$ power. According to Vantelon's experimental work [25], the backlayering length varied by only about height to power one for each value of $Q$, and as HRRs were very small, it should be developed more theoretically and mathematically. Moreover, the proposed equation cannot correlate all the test results. A clear disadvantage of formulations proposed by Thomas and Vantelon is that the dimensionless backlayering length becomes zero when the Froud number is infinity or the dimensionless HRR is zero though, in an actual situation, the backlayering length is zero in conditions of finite Froud number or dimensionless HRR more than zero. As a result, these 
equations do not have enough accuracy in the mentioned situation. The fundamental characteristics of the smoke flow (entrainment, stratification, and recirculation) developing in a metro tunnel near a station was described in the second part of Vantelon's experiment [25]. The main objective of his experiments was extracting some information to prevent the diffusion of the smoke flow.

A set of experimental tests were implemented in a tunnel with ceramic fiberboard boards by Yamada et al. [26]. The cross section of this tunnel was rectangular and its aspect ratio was unity. Yamada et al. showed that $L_{b} / H$ depends on one-third power of dimensionless heat release rate in the range of $L_{b} / H>10$.

The backlayering length and the critical velocity were also investigated experimentally in a $0.163 \mathrm{~m}$-high model of the Paris metro [27]. According to Deberteix's study [27], the backlayering disappears as the critical Richardson number, which is the ratio of the buoyancy term to the flow shear term, falls below 1 . The derived formula for the backlayering length was as follows:

$$
L_{b}=7.5\left(R i^{1 / 3}-1\right) \text {, }
$$

where $\mathrm{Ri}$ is the Richardson number. Based on (19), the backlayering length is a negative value for a heat release rate of zero, which is not consistent with any physical laws.

$\mathrm{Hu}$ et al. [28] studied the backlayering length and the critical longitudinal ventilation velocity in tunnel fires. Based on a theoretical model and Thomas's theory, they predicted the backlayering length through the temperature rise distribution upstream along the tunnel as well as its dependence on both buoyancy and inertia forces. Temperature rise was calculated through two steps: first, the maximum smoke temperature was predicted and then the correlation between temperature decay versus distance from the fire and the maximum temperature was calculated. The backlayering length, $L_{b}$, was deduced from the following equation:

$$
L_{b}=\frac{\ln \left[K_{2}\left(C_{k} H / V^{2}\right)\right]}{0.019},
$$

with

$$
K_{2}=g \gamma\left(\frac{Q^{* 2 / 3}}{F r^{1 / 3}}\right)^{\epsilon},
$$

where $C_{k}$ is an empirical constant lying from about 0.2 to 0.4 . The backlayering length increases with the fire size and decreases with tunnel height and longitudinal ventilation velocity according to this theoretical analysis. When the backlayering length was set to zero, the critical longitudinal ventilation velocity was also deduced from (20):

$$
U_{C}=\left[C_{k} g H \gamma Q^{* 2 / 3}\left(g H_{d}\right)^{\epsilon / 3}\right]^{1 /(2+2 \epsilon)} .
$$

The values of $\gamma$ and $\epsilon$ depend on $Q^{* 2 / 3} / \mathrm{Fr}^{1 / 3}$ :

$$
\gamma= \begin{cases}1.77 & \text { for } \frac{Q^{*} 2 / 3}{F r^{1 / 3}}<1.35 \\ 2.54, & \text { for } \frac{Q^{*} 2 / 3}{F r^{1 / 3}} \geq 1.35,\end{cases}
$$

$$
\epsilon= \begin{cases}\frac{6}{5} & \text { for } \frac{Q^{*} 2 / 3}{F r^{1 / 3}}<1.35 \\ 0 & \text { for } \frac{Q^{*} 2 / 3}{F r^{1 / 3}} \geq 1.35\end{cases}
$$

The comparison between equation derived by Thomas and measured values in Hu's study shows that (16) underestimates the backlayering length.

A large-scale model tunnel with the completely turbulent flow considering the heat transfer characteristics of the tunnel wall was investigated in Fujita's study [29]. They measured temperature, longitudinal ventilation velocity, and HRR in this experimental study and the dimensionless parameter, $Q^{*} / F r$, was the controlling scaling parameter. The height of the thermal fume layer was measured through the temperature distribution in the direction of the height under the conditions where the backlayering length maintains a stratified layer. They concluded that the thermal fume height upstream from the fire source $\left(H_{d T}^{*}\right)$ decreases linearly with the increase of the parameter $Q^{*} / F r$ by the following equation:

$$
H_{d T}^{*}=-0.183 \frac{Q^{*}}{F r}+0.651,
$$

and the thermal fume height downstream from the fire source decreases exponentially with the increase of the parameter $Q^{*} / F r$ by (25). When the value of parameter $Q^{*} / F r$ was 0.4 or greater, thermal fumes were diffused to the road surface.

$$
H_{d T}^{*}=\exp \left(-11.3 \frac{Q^{*}}{F r}+0.756\right) .
$$

Wood cribs as fuel source were used in a series of scaled experiments with longitudinal ventilation by Ingason and $\mathrm{Li}$ [30]. In this study, the number of wood cribs, longitudinal ventilation rate, and the ceiling height were changed to study different HRR, fire growth rate, maximum gas temperature, and temperature distribution produced by smoke flow under the ceiling. Originally, they simulated the large scale experiments carried out in Runehamar tunnel in September 2003 by Lonnermark [31]. They found that the fuel mass loss rate per unit fuel surface area is related to the ventilation velocity weakly. The average smoke temperature downstream of the fire and the maximum excess gas temperature along the ceiling were also described theoretically. Ingason and $\mathrm{Li}$ [30] proposed a linear regression of this data as follows:

$$
\frac{\Delta T_{c(x)}}{\Delta T_{\max }}=0.9575 e^{\left(-h P x_{f} / \dot{m}_{a} C_{P}\right)} .
$$

However, it should be noted that if the ventilation is too low, (26) was not accurate. The flame lengths from the model scale tests were also compared with several large-scale tests and then they defined a relation between dimensionless flame length and a dimensionless HRR as follows:

$$
L_{b}^{*}=4.3 Q^{*}
$$


They also expressed the dimensionless backlayering length as a function of the dimensionless ventilation velocity as follows:

$$
L_{b}^{*}=17.3 \ln \left(\frac{0.4}{V^{*}}\right)
$$

In addition to the critical velocity, $\mathrm{Li}$ et al. [20] also conducted experimental tests and theoretical analyses to investigate the backlayering length in tunnel fires. Two smallscale experimental test series with different cross section areas were carried out. They used the fact that gas temperature distribution below the tunnel ceiling has an abrupt decrease at the end of the smoke reverse flow to determine the backlayering length by measurement of the gas temperature. It was concluded that the backlayering length varies significantly with the ventilation velocity and that relationship between the backlayering length and the ventilation velocity is not straightforward. The variation of the backlayering length with HRR was clearly demonstrated that the backlayering length increases with $\mathrm{HRR}$ when $\mathrm{HRR}<6.7 \mathrm{~kW}$. However, in large fires, the backlayering length is independent of the dimensionless HRR. Both theoretical analysis and experimental data in Li's study [20] showed that the dimensionless backlayering length can be related to the ratio of longitudinal ventilation velocity to the critical velocity $\left(V^{* *}\right)$, where it follows an exponential relationship:

$$
V^{* *}=e^{\left(-0.054 L_{b}^{*}\right)}
$$

Based on (29) and experimental data, a correlation to predict the dimensionless backlayering length was proposed. The final derived formula from $[20]$ is

$$
L_{b}^{*}= \begin{cases}18.5 \ln \left(\frac{0.81 Q^{* 1 / 3}}{V^{*}}\right) & \text { for } Q^{*} \leq 0.15 \\ 18.5 \ln \left(\frac{0.43}{V^{*}}\right) & \text { for } Q^{*}>0.15\end{cases}
$$

As the fire source was positioned $1.7 \mathrm{~m}$ above the floor in Li's experiment, a higher critical velocity and in turn a longer backlayering length are estimated. The underestimation of the backlayering length can be seen from (29). An experimental study was performed on a $1 / 3$ scale model tunnel by Boehm et al. [32]. Their aim was to investigate the influence of HRR with the introduction of an injector and the presence of vehicles on the smoke layer length and the dimensionless thickness of the smoke layer. Their analyses show that a higher HRR leads to a longer and thicker backlayering layer as observed in large scale tunnel. It should be mentioned that the smoke layer thickness was calculated using the smoke mass flow conservation. They concluded that the vehicles have a great influence in terms of length reduction and thickness increase. However, many authors considered only the difference between the near ceiling temperature and near ground temperature ([33]). Boehm's study developed a new approach to compute the backlayering layer and then evaluate stratification. Boehm's research only considered one physical quantity related to one layer property, which shows some

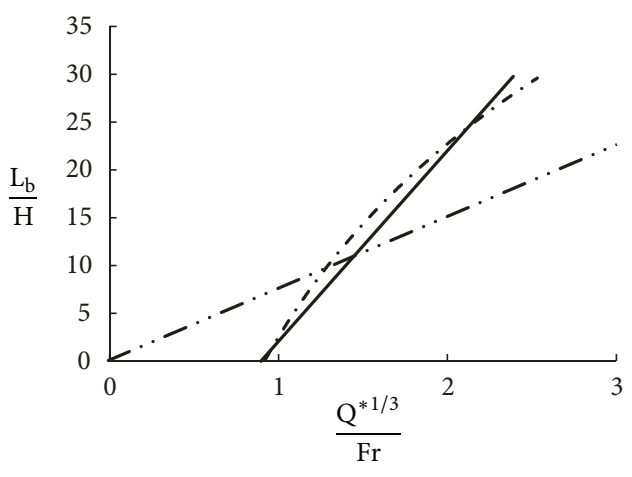

$$
\begin{aligned}
& \text { - Minehero, } 2012 \\
& \text {-.- Hu, } 2008 \\
& \ldots-\text { Vantelon, } 1991
\end{aligned}
$$

FIgURE 5: Comparison between Minehero's [34], Hu's [28], and Vantelon's [25] backlayering results.

limitations in the case of stratification transition regime, e.g., fire in a vehicle upstream.

A large-scale model tunnel was utilized in Minehiro's experiment [34] to examine the critical velocity and the backlayering length experimentally. The similarity of thermal characteristics in model walls and real tunnel walls as well as the Froude number similarity was considered. The backlayering distance was measured by both thermocouples records and visualization of laser beam and then new equation to estimate the dimensionless backlayering distance based on the dimensionless HRR and Froude number, $Q^{* 1 / 3} / F r$, was proposed. The main difference of Minehiro's model was determining new parameters, and $d$ and $e$ were obtained from experimental data by using the least-squares method. Parameter $d$ has the same role as parameter $c$ in (17) and parameter $e$ was introduced to calculate the backlayering distance with sufficient accuracy by using a finite Froude number or a dimensionless HRR higher than zero when the dimensionless backlayering distance approaches zero. These constants were derived: $d=20$ and $e=18$, respectively. Equation (31) was extracted to determine the backlayering length with the dimensionless heat release rate ranging from 0.0316 to 0.111 .

$$
\frac{L_{b}}{H}=d\left(\frac{Q^{*}}{F r^{3}}\right)^{1 / 3}-e .
$$

Moreover, Minehero et al. compared the results of their study with Hu's [28] and Vantelon's [25] experimental data in the dimensionless heat release rate ranging from 0.0316 to 0.182 (Figure 5). This graph shows that (18) derived by Vantelon was not in agreement with Hu's and Minehero's results. On the other hand, (20) with $C_{k}=0.3$ was in agreement with black line, Minehero's equation (31). However, the backlayering length was overestimated for the dimensionless heat release rate more than 0.111 . [34].

The smoke layering length both upstream and downstream was examined in Chen's study [35]. In their study, a tunnel fire with combination of point extraction and longitudinal ventilation was investigated. The flow velocity 
affected by point extraction was taken into account to develop a theoretical model which has a modified HRR as well as modified upstream and downstream opposing longitudinal air flow velocities. In addition, a series of experiments with various HRR, point extraction rates, and longitudinal ventilation velocities were carried out. The main results were as follows:

(1) The smoke layering length was longer downstream compared with the upstream's one

(2) Although the increase in ventilation velocity causes an increase in the downstream backlayering length, the upstream smoke layering length reduces when ventilation velocity increases

(3) Both upstream and downstream layering length decrease with increase in point extraction velocity.

As control of smoke flow in a tunnel equipped by both longitudinal ventilation and transverse exhausting system was not considered deeply, the issue of the smoke backlayering length in longitudinal ventilated tunnel fires with vertical shaft in the upstream was considered in the works by Yao et al. [36]. To predict the smoke backlayering length in their model, Yao et al. [36] first developed an empirical model by introducing the virtual fire source below the vertical shaft. Yao et al. [36] used (30) derived by Li et al. [20] and modified HRR and ventilation velocity to introduce a new formula for the dimensionless smoke backlayering length beyond the shaft which is

$$
\begin{aligned}
L_{b}^{*} & =\frac{L_{b}}{H} \\
& = \begin{cases}18.5 \ln \left(\frac{0.81 \dot{Q}_{\text {virtual }}^{* 1 / 3}}{U^{*}}\right) & \text { for } \dot{Q}_{\text {virtual }}^{* 1 / 3} \leq 0.15 \\
18.5 \ln \left(\frac{0.43}{U^{*}}\right) & \text { for } \dot{Q}_{\text {virtual }}^{* 1 / 3}>0.15,\end{cases}
\end{aligned}
$$

with

$$
\begin{aligned}
Q_{\text {virtual }}^{*} & =\frac{2\left(\left[\dot{Q}_{u p}-\dot{Q}_{\text {exhaust }}-\dot{Q}_{\text {loss }}\right] /\left(1-x_{r}\right)\right)}{\rho_{a} C_{P} T_{a} g^{1 / 2} H^{5 / 2}} \\
U^{*} & =\frac{V+\rho_{d} \omega S_{e} / 2 A \rho_{a}}{\sqrt{g H}} .
\end{aligned}
$$

Based on experimentation and its subsequent analyses, they concluded that

(1) the dimensionless backlayering length decreased with the increase of ventilation velocity, whereas it increased with a higher HRR

(2) the distance between the fire source and the vertical shaft had a significant effect on the smoke backlayering length; when fire source is moving away from the vertical shaft (within dimensionless distance), the backlayering length decreased

(3) prediction from formula and experimental data were compared; the model prediction fitted reasonably well

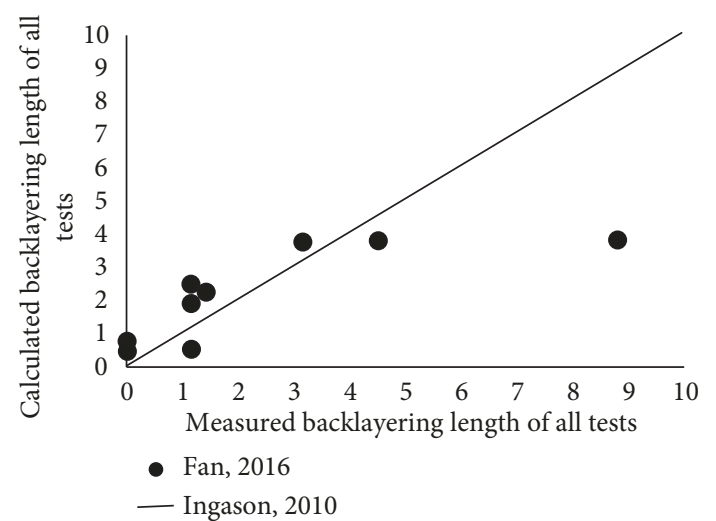

FIgURE 6: Comparison between Fan et al. [7] and Ingason and Li [30] backlayering results.

when the dimensionless longitudinal air flow velocity is less than 0.19 .

It should be noted that their empirical model overestimates the convective heat spread at the upstream section in higher longitudinal ventilation velocities.

In the following, Fan et al. [7] established an integral model of backlayering length including the impact of both tunnel height and width. In this study, the effects of tunnel height and width on the backlayering length were analyzed emphatically in experiments with large heat release rates, where the flame impinges on the tunnel ceiling. New dimensionless form of backlayering length was proposed as follows:

$$
L_{b}^{*}=30-79 V^{\prime} \text { for } V^{\prime}<0.38
$$

where

$$
V^{\prime}=\frac{V}{\sqrt{g H}} .
$$

Their major conclusions were as follows:

(1) In situations with the same fuel and ventilation velocity but greater tunnel cross-sectional area, an increase in the tunnel cross-sectional area led to greater backlayering length

(2) The backlayering length became shorter with the increasing ventilation velocity

The contrast between the equation derived by Ingason and $\mathrm{Li}$ [30] and Fan et al. [7] indicates that there is at least $20 \%$ deviation between them (Figure 6).

Main parameters which affect backlayering length are heat release rate, ventilation velocity, tunnel geometry, ambient properties, and gravitational acceleration. These parameters can be summarized in the dimensionless heat release rate and Fraud number, which are considered by many researchers to study backlayering length. 


\section{Blockage Effect}

The mentioned models for measuring the critical velocity and the backlayering length in Sections 2 and 3 considered tunnel fire without blockage effect. However, in most actual tunnel fires, vehicles are usually stuck in the tunnel when a fire occurs and it spreads between vehicles. A vehicle plays the role of obstacle in the longitudinally ventilated tunnel, which will impact the local velocity around the fire source remarkably. Consequently, fire plume behaviour is changed accordingly.

In addition to examining the relationship between HRR and the critical velocity, Oka and Atkinson [11] investigated the effect of blockage on the critical velocity. They found out that a noticable decrease happend in the critical velocity value when a solid blockage was placed in the tunnel. In their experimental model, around $12 \%$ of cross section area of tunnel was occupied by a blockage, in which, in turn, a decrease of around $15 \%$ in the critical velocity occurred. Moreover, when the vehicle occupies $32 \%$ of the tunnel cross section area, $40-45 \%$ reduction of the critical velocity appears. This reduction is due to the decrease of air entertainment to the fire size. Although the results of their experiments were influenced by the cooling system used, it can be concluded that the reduction ratio of the critical velocity is greater than the ratio between the cross-sectional area of the tunnel and the cross-sectional area of vehicles. The conclusion of Oka and Atkinson's study about the effect of vehicles on the critical velocity is not a comprehensive result because they investigated one tunnel section.

The effects of accident vehicle obstruction on the critical velocity and backlayering length were also analyzed in [20]. $\mathrm{Li}$ et al. [20] positioned a model vehicle of $8 \mathrm{~m}$ long, $0.15 \mathrm{~m}$ wide, and $0.2 \mathrm{~m}$ high and a series of experiment were carried out in a $12 \mathrm{~m}$ long model tunnel. They derived relationship between the dimensionless critical velocity and the dimensionless HRR, when the model vehicle occupies $20 \%$ of the tunnel cross-sectional area:

$$
V_{\text {blockage }}^{*}= \begin{cases}0.63 Q^{* 1 / 3} & \text { for } Q^{*} \leq 0.15 \\ 0.33 & \text { for } Q^{*}>0.15\end{cases}
$$

According to Li's analyses [20], the reduction ratio of the critical velocity due to obstruction was slightly greater than the ratio of cross-sectional area of obstructions to tunnel cross-sectional area. Although the location of the fire source was under the vehicle in Li's experiment [20] and was outside of the vehicle in Oka and Atkinson [11], both experiments obtained the same result regarding the influence of blockage on the critical velocity. They also compared the results of the critical velocity in the presence of vehicles with Wu and Bakar study [13] (Figure 7). They concluded that when the blockage ratio increases, the critical velocity decreases. Moreover, the changes of dimensionless backlayering length against the dimensionless confinement velocity were investigated and they showed that the backlayering length reduces when a model vehicle is placed inside tunnel. The dimensionless

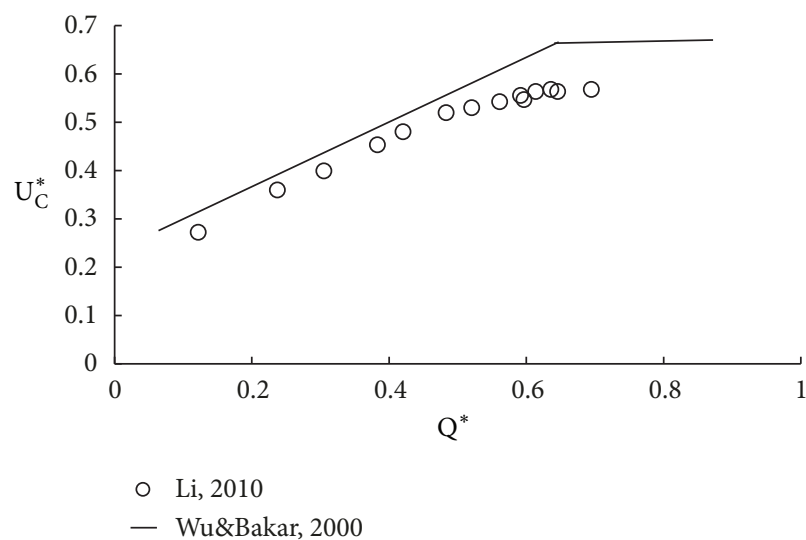

FIGURE 7: Dimensionless critical velocity with and without blockage.

backlayering length correlated well with the following equation in this study:

$$
L_{\text {blockage }}^{*}= \begin{cases}13.5 \ln \left(0.63 R i^{1 / 3}\right) & \text { for } Q^{*} \leq 0.15 \\ 13.5 \ln \left(\frac{0.33}{V^{*}}\right) & \text { for } Q^{*}>0.15 .\end{cases}
$$

Considering that in the past studies one constant blockage ratio was examined, Lee et al. [37] studied the effect of obstacles on tunnel fire behaviour through three different vehicle sizes in two or three arrays occupying 5-31\% of the tunnel cross-section area. Flame shape and its characteristics were investigated in the presence of vehicles in various distances to the fire source. Moreover, FDS was applied to analyze the flow behavior of longitudinal ventilation obstructed by vehicles in a tunnel. They concluded the following:

(1) HRR was proportional with vehicle size.

(2) $U_{c}$ had an inverse relationship with vehicle size when the ventilation flow reached fires directly. However, if ventilation velocity did not reach fire directly, $U_{c}$ was proportional with vehicle size.

(3) The change ratio of $U_{c}$ increased as the tunnel blockage ratio increased for fires downstream of vehicles. For fires located on the tunnel center line, the change ratio of $U_{c}$ was smaller than the tunnel blockage ratio. The largest vehicle blockages and fire source located downstream of blockages lead to the highest critical velocity.

(4) When fire is located downstream of obstacles, the flame shape was different than fire scenarios without blockages.

It should be noticed that this experimental result was not in agreement with that proposed by Li et al. [20]. According to Li's study [20], the change ratio of $U_{c}$ was slightly greater than the tunnel blockage ratio. In addition, the fire source was under the vehicle in Li's experiment while blockages were positioned upstream of the fire source in Lee's study. The location of obstacles to the fire source influences the local ventilation velocity and in turn the decrease of the critical 
velocity in the presence of vehicles was less than the decrease reported by Li et al.

Experiments were also conducted in a model tunnel to investigate the effect of upstream vehicular blockage and blockage-fire distance on the buoyancy driven backlayering length and the critical velocity [38]. Tang et al. [38] investigated different factors such as HRR, longitudinal ventilation velocities, and blockage-fire distances. First, they compared the experimental results of backlayering length and the critical velocity in the case of no blockage with formula derived by $\mathrm{Wu}$ and Bakar [13] and Li et al. [20], respectively. They found that these data can be well collapsed in Wu's and Li's models $([13,20])$. Then, based on Lee's analysis [37] and experimental results of local velocity in the vicinity of fire source, which is affected by blockage ratio of the crosssection area, Wu and Bakar's model and Li et al's model were revised by adding cross-sectional blockage ratio. The corrected equations were

$$
V_{\text {blockage }}^{*}= \begin{cases}\frac{0.4}{\alpha}\left(\frac{Q^{\prime}}{0.2}\right)^{1 / 3} & \text { for } Q^{\prime} \leq 0.2 \\ \frac{0.4}{\alpha} & \text { for } Q^{\prime}>0.2,\end{cases}
$$

$$
L_{\text {blockage }}^{*}= \begin{cases}18.5 \ln \left(\frac{0.81 Q^{* 1 / 3}}{\left(\alpha V^{\prime}\right)}\right) & \text { for } Q^{\prime} \leq 0.15 \\ 18.5 \ln \left(\frac{0.43}{\left(\alpha V^{\prime}\right)}\right) & \text { for } Q^{\prime}>0.15\end{cases}
$$

where $\alpha$ is tunnel blockage ratio, which is the ratio of the difference between the tunnel cross section and the obstacle cross section to the tunnel cross section. The comparison between the experimental results of this study and modified Wu model and modified Li model shows that these modified models can estimate backlayering length in the situations with small blockage-fire distance. However, both cannot well predict backlayering length when the blockage-fire distance increased. Therefore, a dimensionless modification coefficient, which was correlated nondimensionally with the normalized blockage-fire distance, was presented in Tang et al. [38]. This coefficient was then added in (38) to develop new global models considering both the blockage ratio and the blockage-fire distance:

$$
\begin{aligned}
& V_{\text {blockage }(L)}^{*}= \begin{cases}\frac{0.4}{\left[\left(A-A_{2}\right) / A+\left(A_{2} / A\right)\left(0.3 L_{b} / \bar{H}\right)\right]}\left(\frac{Q^{\prime}}{0.2}\right)^{1 / 3} & \text { for } Q^{\prime} \leq 0.2, \quad L_{b} \leq 3.3 \bar{H} \\
\left.\frac{Q^{\prime}}{0.2}\right)^{1 / 3} & \text { for } Q^{\prime} \leq 0.2, \quad L_{b}>3 \bar{H} \\
\frac{0.4}{\left[\left(A-A_{2}\right) / A+\left(A_{2} / A\right)\left(0.3 L_{b} / \bar{H}\right)\right]} & \text { for } Q^{\prime}>0.2, \quad L_{b} \leq 3.3 \bar{H} \\
0.4 & \text { for } Q^{\prime}>0.2, \quad L_{b}>3 \bar{H},\end{cases} \\
& L_{\text {blockage }(L)}^{*}= \begin{cases}18.5 \ln \left(\frac{0.81 Q^{* 1 / 3}}{\left(\left[\left(A-A_{2}\right) / A+\left(A_{2} / A\right)\left(0.3 L_{b} / \bar{H}\right)\right] V^{\prime}\right)}\right) & \text { for } Q^{\prime} \leq 0.15, L_{b} \leq 3.3 \bar{H} \\
18.5 \ln \left(\frac{0.81 Q^{* 1 / 3}}{V^{\prime}}\right) & \text { for } Q^{\prime} \leq 0.15, L_{b}>3.3 \bar{H} \\
18.5 \ln \left(\frac{0.43}{\left(\left[\left(A-A_{2}\right) / A+\left(A_{2} / A\right)\left(0.3 L_{b} / \bar{H}\right)\right] V^{\prime}\right)}\right) & \text { for } Q^{\prime}>0.15, L_{b} \leq 3.3 \bar{H} \\
18.5 \ln \left(\frac{0.43}{V^{\prime}}\right) & \text { for } Q^{\prime}>0.15, L_{b}>3.3 \bar{H} .\end{cases}
\end{aligned}
$$

Here, $b l \mathrm{~kg}$ is blockage, for simplicity.

It is concluded that the process of changing of the backlayering length and the critical velocity was the same [38]; when the distance between blockages and the fire source increased, backlayering length and the critical velocity first decreased and then were maintained to a constant value. This trend also occurred in the situation with no blocks. In addition, a new global model was proposed, which can predict experimental measurements for different blockage-fire distances accurately compared to the experimental results of the above global models. In order to examine the effect of blockages as well as their distance to the fire source on the maximum smoke temperature, $\mathrm{Hu}$ et al. [39] also carried out an experiment in a longitudinally ventilated tunnel. This study was carried out based on the method used by $\mathrm{Li}$ et al. [40]. However, a modification coefficient considering the impact of blockagefire distance was added. Then, a global model including both blockage ratio and blockage-fire distance was developed as follows: 


$$
\Delta T_{\max }= \begin{cases}\frac{Q}{\left[\left(A-A_{2}\right) / A+\left(A_{2} / A\right)(0.3 L / \bar{H})\right] V r^{1 / 3} H_{d}^{5 / 3}} & \text { for } V^{\prime}>0.19, L<3.3 \bar{H} \\ \frac{Q}{V r^{1 / 3} H_{d}^{5 / 3}} & \text { for } V^{\prime}>0.19, L \geq 3.3 \bar{H} \\ 17.5 \frac{Q^{2 / 3}}{H_{d}^{5 / 3}} & \text { for } V^{\prime} \leq 0.19 .\end{cases}
$$

It is deducted that if obstacles were positioned at downstream section of a tunnel, the maximum gas temperature was not influenced. However, the maximum temperature decreased and then approached a constant value (similar to that with no blockage) with an increase in blockage-fire distance.

With regard to ceiling temperature distribution and smoke diffusion distance in tunnel fires with natural ventilation and train blockage, a series of experimental tests was carried out by Kashef et al. [41]. Two scaled models with different material and length were used. They proved theoretically that in the fire section and the nonfire section of the tunnel, the smoke temperature can be expressed using the temperature decay formula and reference temperature formula. Moreover, the dimensionless smoke temperature and a constant value, which was different for investigated different tunnels in this paper, were used to derive the reference temperature in the fire section. The above analysis of the temperature decay was operational for expecting the smoke parameters of a real tunnel.

In addition to examining the effect of the vehicles on the smoke flow in tunnels, the effect of the metro train blockage on the smoke backlayering in the subway tunnel fire was investigated by some researchers, such as Zhang et al. [42], using both theoretical analysis and small-scale tunnel experiments. Theoretical analysis in [42] was carried out on three different cases: without blockage, with short blockage, and with long blockage. A new physical model including the factor of metro train length was developed to predict the backlayering length in the tunnel based on the hot gases temperature distribution and fire dynamics theory.

$$
L_{b}^{*}= \begin{cases}6.956 \ln \left(\frac{1.712 Q^{* 1 / 3}}{V^{\prime} /(1-\alpha)}\right) & \text { for } Q^{* 1 / 3} \leq Q_{L=L_{T}}^{* 1 / 3} \\ \frac{L_{T}+L_{b}}{\bar{H}}=\frac{L_{T}}{\bar{H}}+19.342 \ln \left(\frac{0.935}{Q_{b-T}^{* 1 / 3} V^{\prime}}\right) & \text { for } Q^{* 1 / 3}>Q_{L=L_{T}}^{* 1 / 3}\end{cases}
$$

where the dimensionless heat release rate $Q_{L=L_{T}}^{*}$ is determined by the train length $L_{T}$ as follows:

$$
\begin{aligned}
Q_{L=L_{T}}^{* 1 / 3} & =0.584 \frac{V^{\prime}}{1-\alpha} e^{\left(L_{T}^{*} / 6.956\right)}, \\
L_{T}^{*} & =\frac{L_{T}}{\bar{H}} .
\end{aligned}
$$

Then, the smoke backlayering was studied through a series of small-scale experiments in a tunnel with a metro train and the results showed that the backlayering length was significantly influenced by the metro train. There are differences between Tang's model [38] and Zhang's one [42]. Figure 8 shows that Tang's model underpredicts the experimental results of backlayering length with a train blockage, which is because of the significant effect of such a long blockage.

In order to broaden the knowledge of backlayering characteristics in case of tunnel fire with obstacles, particularly considering the effect of different blockage-fire distances, Tang et al. [43] studied the influence of different distances between the fire source and blockages on the hot gases layer thickness in a longitudinal ventilated tunnel experimentally. Various longitudinal ventilation velocities, HRR, and blockage-fire distances were considered and it is concluded that

(1) the vertical temperature of hot gases near the tunnel ceiling was decreased when the longitudinal ventilation velocity increased

(2) an increase in ventilation velocity led to thicker smoke layer due to strengthened air entrainment and mixing capability, regardless of the presence or absence of blockages

(3) the backlayering thickness was smaller in a tunnel with vehicular blockages; however, it increased with increasing blockage-fire distance as the air entrainment was restricted with blocks.

A set of scaled experiments were performed by Alva et al. [44] to investigate the impact of vehicular blockage on the controling of smoke flow by longitudinal ventilation. A buoyant jet of a helium-air mixture with different flow rates in a $4.65 \mathrm{~m}$ long model tunnel was used as the fuel utilized [44]. Consequently, several blockage ratios were achieved ranging 


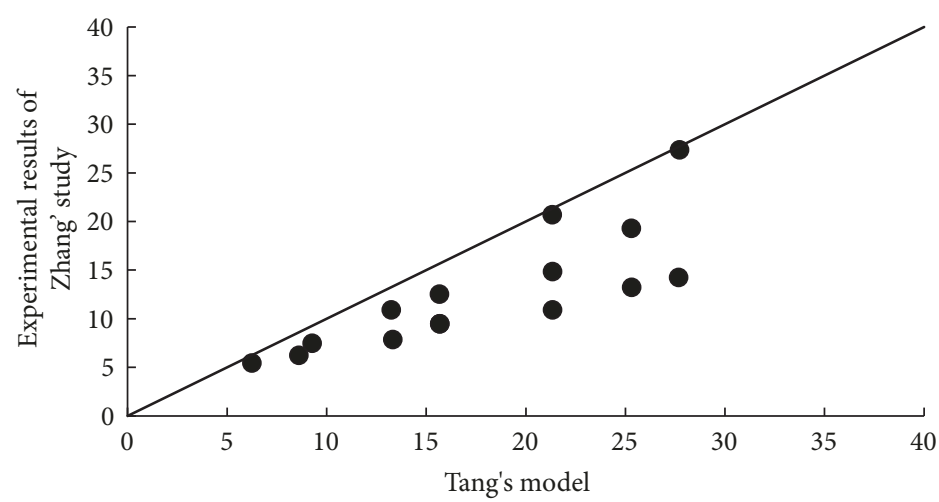

FIGURE 8: Zhang's experimental results [42] vs. Tang's model [38].

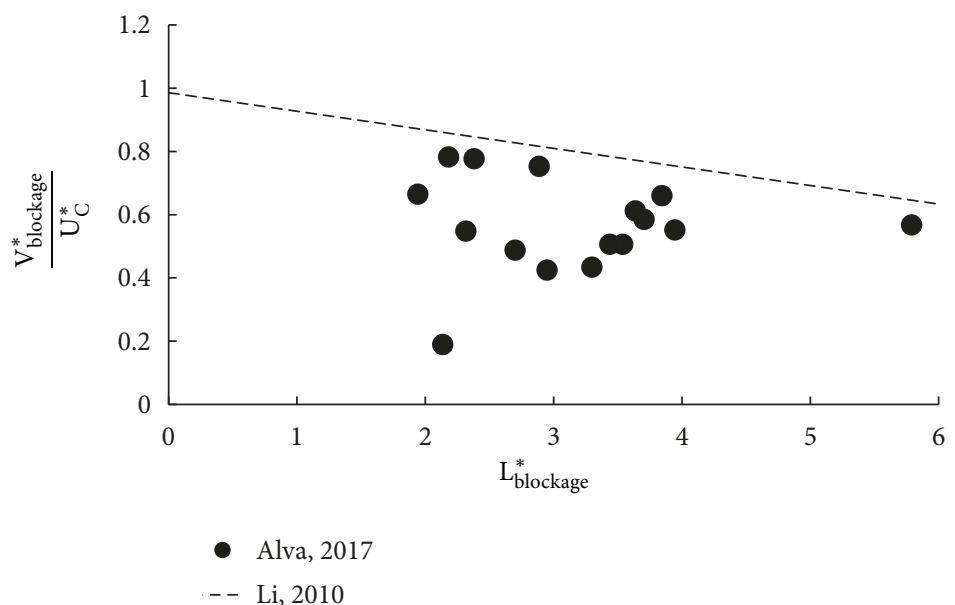

FIGURE 9: The comparison of dimensionless backlayering length with blockages vs. the confinement velocity presented in [45].

from 10.3 to $41 \%$. Several HRRs, fire source positions, blockage ratios, and tunnel dimensions were examined. The comparison between overall results that correspond to the critical velocity without blockage ratio and full scale experiments obtained good agreement. They concluded that when vehicles occupied a tunnel cross-section area, the critical velocity decreased following the correlation proposed by $\mathrm{Li}$ et al. [20] if the longitudinal air flow reached directly the fire plume but when the fire plume is partly blocked by blockage, then the critical velocity did not follow the reference correlation. In addition, the tunnel model correlates well with dimensionless backlayering distance reference correlation proposed by [20].

The effect of vehicular blockages on the backlayering distance and longitudinal ventilation system was also studied systematically [45]. In this experiment, a buoyant plume of helium-air was used by Alva et al. [45] to investigate smoke movements in a ventilated tunnel. The ceiling and walls of tunnel were adjustable to study several blockage ratios, which occupied $10.3 \%$ to $41 \%$ of tunnel cross-section area. Alva et al. [45] determined that the critical velocity decreased as a function of the blockage ratio. However, the size of obstacle and its relative distance to the fire source could have a reversed effect because the ventilation flow might be partly blocked on its way to reach the fire source. With regard to backlayering length, the obtained results did not match with the reference correlation proposed by Li et al. [20] in the existence of obstacles. This difference was due to different blockage ratio in $\mathrm{Li}$ et al. [20] while various blockage ratios and fire positions were considered in Alva et al. [45] (Figure 9). On the other hand, as small fires were studied in this paper ranging from 0.42 to $5.3 \mathrm{MW}$ in full scale, further thermal experiments are needed in order to find the most appropriate and suitable correlations for both the critical velocity and backlayering length in case of existence of blockage.

Although there are numerical differences in results derived from various studies, the influence of blockages on the critical velocity, backlayering length, and the maximum temperature is negligible because the existence of obstacles impacts the amount of air entrainment and local velocity in the vicinity of the fire source. It should be considered that the position of blockages related to the fire source and the distance between the fire source and obstacles need more investigations. 


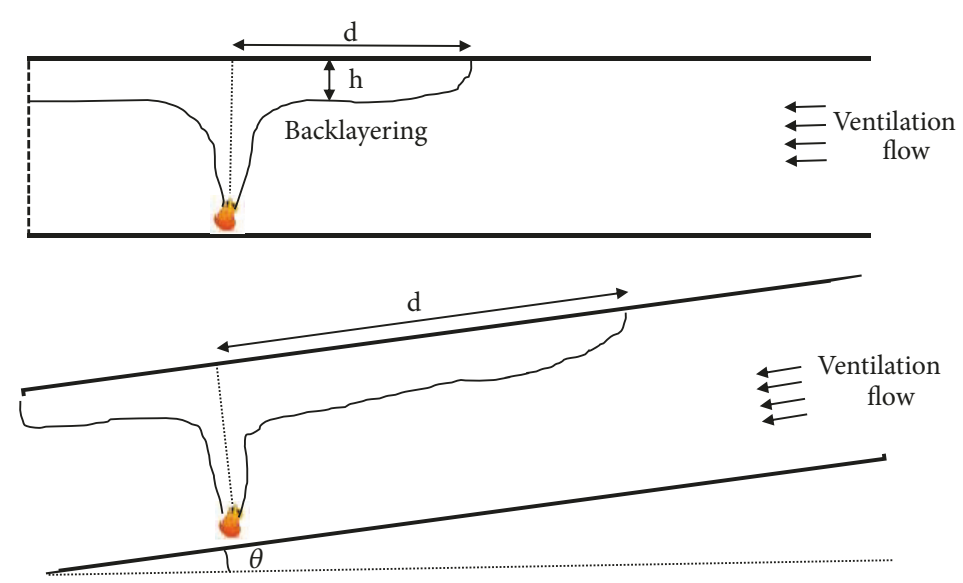

FIGURE 10: Effect of slope on backlayering length.

\section{Slope Effect}

Investigating tunnel fires without considering the effect of slope in railway tunnels leaves one of the most important parameters unaccounted for. When tracks are installed on open fields approaching an underground station, tunnels must have inclinations. The slope of the tunnel will significantly affect smoke movement under fire due to buoyancy and stack effect. It will also affect the critical velocity as well. According to previous studies, the critical velocity might be higher for downhill slope and smaller for uphill slope than that in the horizontal tunnel due to the effect of buoyancy. These are shown in Figure 10.

In regard to the influence of slope on the critical velocity, experimental research involving model tunnels with slopes between 0 and 10 degrees was carried out by Atkinson and $\mathrm{Wu}$ [46]. Atkinson and Wu [46] used a scaled model tunnel with downhill slopes and carried out a series of experimental tests to extend the work of Oka and Atkinson [11]. The slope of the model tunnel was controlled by a series of brackets between 0 and $10^{\circ}$. The critical ventilation velocity in this study was defined with regard to the ventilation velocities required to control the length of the "backlayering" smoke flow to 1, 3, 5, and 10 times the tunnel heights. Wu and Atkinson concluded that the critical velocity to control the backlayering length at 1 and 3 times of the tunnel heights,increases steadily with the increase of the tunnel slope. However, the trend of the critical velocity to eliminate backflow length at 5 or 10 times of the tunnel heights is vice versa. In addition, when the slope was changed from 0 to $4^{\circ}$, the critical velocity almost became independent of the slope. The derived equation for the critical velocity in this study has a slope correction factor based on the experimental results to modify the effect of the downhill slope.

$$
\begin{aligned}
& U_{C} \\
& = \begin{cases}g H^{1 / 2} V_{\max }^{*}\left[\frac{Q^{*}}{1.2}\right]^{1 / 3}[1+0.014 \theta] & \text { for } Q^{*} \leqslant 0.12 \\
g H^{1 / 2} V_{\text {max }}^{*}[1+0.014 \theta] & \text { for } Q^{*}>0.12 .\end{cases}
\end{aligned}
$$

An angle is measured in degrees and $\theta$ is the angle of tunnel slope in degrees and the values taken by $V_{\max }^{*}$ for different fire source with and without tunnel blockages were discussed in [11].

It should be noted that, in Atkinson and Wu study, they used a propane fire source with fixed HRR. Therefore, the changes in the burning rate due to ventilation velocity and its effect on the critical velocity were ignored. In the case of evaluating the critical velocity for several buoyant source characteristics and several channel geometries and slopes, Vauquelin [47] performed experiments with a laboratory model. He used a mix of air and helium continuously released from a circular nozzle as a buoyant source. A review of theoretical and semiempirical models available in the literature for critical conditions was also proposed [47]. Also, with regard to the influence of tunnel slope on the critical velocity, the channel slope of $\pm 16^{\circ}$ was used by Vauquelin [47]. The results of the inclined tunnel were then compared with the relation proposed through [2]. A perfect agreement was observed between experimental values and Atkinson's correction factor. He concluded that the slope effect simply corresponds to a linear correction of the critical velocity in the slope range of study which means a linear correction of the critical velocity regarding the slope effect. A reduced scale model tunnel with varied tunnel slope was also experimented by Ko et al. [48] to investigate the effect of tunnel slope on the critical ventilation velocity considering the change in HRR in tunnel fire. Five inclinations of $0,2,4,6$, and $8^{\circ}$ were adopted as tunnel slope. The main results of this study are as follows:

(1) When the tunnel slope increased, the influence of tunnel ceiling was declined which, in turn, led to longer backlayering length at the given ventilation velocity

(2) The smoke diffusing velocity was also increased by the inclination of the tunnel due to the stack effect

(3) The stack effect related to tunnel slope caused an increase in the critical velocity.

The comparison between Atkinson and Wu's [2] experiment and Ko et al. [48] study shows that Ko's experiment 


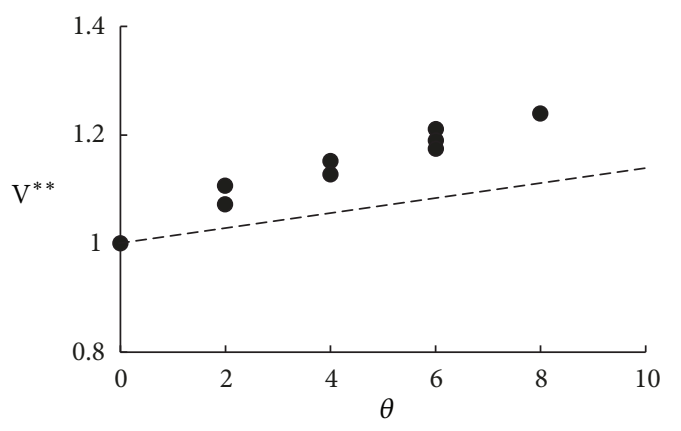

- Ko, 2009

- - Atkinson \& Wu,1996

FIGURE 11: Normalized critical velocity as a function of tunnel slope, comparison between Ko et al. results [48] and Atkinson and $\mathrm{Wu}$ research [2].

illustrated higher critical velocities than Atkinson and Wu's relationship, as Figure 11 shows. This difference is because of the difference of the experimental conditions as Atkinson and $\mathrm{Wu}$ used propane gas burner with constant burning rate and, in addition, the tunnel ceiling of their study was cooled by water spray. Furthermore, Ko et al. compared the results of dimensionless critical velocity of their study with $\mathrm{Wu}$ and Bakar [13] which indicated that Wu and Bakar model underestimates the dimensionless critical velocity.

Then, a new relationship between the critical velocity and the angle of tunnel slope was derived, i.e.,

$$
\begin{aligned}
V^{* *} & =\frac{V_{C, \theta}}{U_{C}}, \\
V^{* *} & =(1+0.033 \theta) .
\end{aligned}
$$

The smoke movement pattern in a tilted tunnel model was investigated in chow's study [4]. In this experimental study, a 1:50 tunnel model $2 \mathrm{~m}$ long with an adjustable angle to the horizon was used by Chow et al., whose structure was constructed by acrylic pieces. They found out that the shape of the buoyant plume depended on the tilting angle of the tunnel. The bending angle of the plume also depended on the tunnel angle. Therefore, a larger tilted angle would give a larger amount of smoke flowing in the tunnel due to buoyancy.

As the effect of tunnel slope on the fire-induced hot gas temperature profile beneath the ceiling has not been clarified nor included in existing models, $\mathrm{Hu}$ et al. [49] carried out experiments in a reduced scale model tunnel, and its slope varied at three typical different angles, 0,3 and $5^{\circ}$. In this study, both the maximum gas temperature and the temperature distribution along the tunnel ceiling were measured and compared with previous models. They analyzed the current models $([40,50,51])$ to modify the equations to include the tunnel slope factor. It can be observed from the results of their slopped model that

(1) the maximum gas temperature decreases as the tunnel slope increases
(2) the gas temperature decays much faster with distance when the tunnel slope is higher.

The correlation results suggested the following equations:

$$
\begin{aligned}
& \Delta T_{\text {max }}= \begin{cases}(1-0.067 \varphi) \frac{Q^{\prime}}{V r^{1 / 3} H_{d}^{5 / 3}} & \text { for } V>0.19 \\
(1-0.061 \varphi) \frac{17.5 Q^{\prime 2 / 3}}{H_{d}^{5 / 3}} & \text { for } V \leq 0.19\end{cases} \\
& \frac{\Delta T_{x}}{\Delta T_{\max }}=\frac{T_{x}-T_{a}}{T_{\max }-T_{a}}=e^{-(1+0.09 \varphi) K x_{f}}
\end{aligned}
$$

where

$$
K=-\frac{\lambda}{\rho h V} .
$$

In order to study the backlayering length and the critical velocity of smoke in the metro tunnel with different sectional coefficients, longitudinal ventilation velocities, HRRs, and tunnel slopes, the method of dimensionless analysis and the FDS simulation were used by Weng et al. [52]. In the experiment, 45 small-scale models were carried out to provide verification of CFD simulations. The experimental results show a good agreement with the numerical simulations. A new formula for the critical velocity was proposed for the tunnels with different slopes. The results were then analyzed and found to fit the following:

$$
\frac{V_{C, \theta}}{U_{C}}= \begin{cases}1+1.008 \varphi & \text { for } \xi \geq 1, \\ 1+2.355 \varphi & \text { for } \xi<1\end{cases}
$$

Moreover, the prediction models for the critical velocity on different slopes were compared with the prediction models proposed by Atkinson and $\mathrm{Wu}$ [2], Ko et al. [48], and Chow et al. [4]. It was shown that the results of the proposed model by Weng [52] were between Atkinson and $\mathrm{Wu}$ and Chow because of different aspect ration. A set of full-scale experiments was conducted by Yu et al. [53] to study thermal and smoke control strategies using transverse ventilation system in a sloping urban traffic link tunnel. They recommended an optimal smoke control strategy by analyzing smoke propagation velocity, smoke traveling distance, and longitudinal temperature distribution. The major conclusions were summarized as follows:

(1) In the process of the emergency ventilation velocity design, which includes the efficient control of smoke exhaust by air supply vents, the effect of tunnel slope should be taken into account

(2) Supplying the ventilation air from the downstream of fire and exhausting the smoke within its downstream smoke compartment is the ideal strategy for transverse ventilation in slopping tunnel.

Due to the effect of the slope of the tunnel on the shape of the flame, smoke movement, and flame bending, the 
difference in critical velocity and smoke characteristics in tunnels with different slopes is predictable. As it is reported when the tunnel slope increases, longer backlayering length and bigger critical velocity are observed. Since studies in the effect of tunnel slope on the smoke temperature are insufficient, more research is needed on this study.

\section{Fire Location Effect}

The critical ventilation velocity and the backlayering characteristics were studied in previous studies in the case of one fire source which was located in the longitudinal center of tunnels. In fact, fires can occur anywhere inside the tunnel, for example, near the tunnel exit, and the fire source location has a primary effect on the critical ventilation velocity and backlayering characteristics. Therefore, this parameter was conducted by some researchers within the past years. With regard to the impact of different fire source locations on the critical velocity, Tsai et al. [54] investigated this parameter and its influence on the critical velocity experimentally and numerically. In this study, two variously separated fires were experimentally explored and six cases were examined numerically. Both the experimental and numerical data showed that two separated fires could be regarded as a single fire whose burning area is the sum of the areas of the two fires. Additionally, in an experiment, which involved two separated fires, the critical velocity decreased when separation distance increased (a larger upstream fire and a smaller downstream fire). However, when the smaller fire was upstream of the larger fire, the decrease in $U_{c}$ became insignificant as the distance increased. Small-scale experiments to investigate $U_{c}$ were also conducted in Tsai et al. [55] for situations when tunnel fire occurs near tunnel exits. Tsai et al. studied a $4 \mathrm{~m}$ long scaled tunnel and investigated 3 different fire source locations from the tunnel exit. The results of this study showed that the critical velocity declined when the fire source approached the tunnel exit due to the decreasing natural resistance between the fire and the ventilation flow. Another approach of these results was that experimental fires in tunnels have to be designed with sufficient distance between the fire and the downstream portal to avoid this exit effect on $U_{c}$.

Regarding the effect of fire source near the sidewall on the critical velocity, $\mathrm{Hu}$ et al. [56] carried out theoretical and numerical analysis. The theoretical results of this study show that when the fire is located near the sidewall, the critical velocity was approximately 1.6 times as much as the source of the fire in the center of the tunnel. However, this ratio was 1.18 by CFD modeling. The comparison between this study and Oka and Atkinson [11], Wu and Barker [13], and Kunsch [15] indicates that those previous studies underestimated the critical velocity for cases with fire near the tunnel sidewall.

Recently, Tsai et al. [55] continued Fan et al. [6] work to demonstrate the relationship between the critical velocity and the longitudinal length between the fire and tunnel exit. Quantitative and graphical analyses were performed to explain the smoke flow characteristics without longitudinal ventilation as well as under the critical ventilation velocity when the fire source was positioned at three different longitudinal distances to the tunnel exit. A quantitative correlation between the critical ventilation velocity and the distance between the fire source and tunnel exit was extracted as follows:

$$
\frac{U_{C, Y}}{U_{C}}=\frac{0.177 Y}{H_{d}}+0.396,
$$

where $H_{d}$ is the height from fire source to the tunnel ceiling. Moreover, the effect of longitudinal fire location on maximum smoke temperature under the ceiling was investigated in this research since the enhancement of tunnel safety was influenced by the impact of the maximum smoke temperature beneath the tunnel ceiling. Results showed that the maximum smoke temperature was not obviously affected by longitudinal fire location.

As the influence of the distance between the ceiling opening and heat source on backlayering length had not previously been studied, Chen et al. [3] performed a series of experiments in a reduced-scale tunnel to measure the backlayering length in this situation based on [20]. They concluded that the backlayering length increased with the heat source-ceiling extraction (opening) distance. Furthermore, a new theoretical model was deducted to predict the backlayering length with the heat source-extraction (opening) distance included [3].

$$
L_{b}= \begin{cases}18.5 H \ln \left(\frac{0.81 \dot{Q}^{* * 1 / 3}}{V^{* *}}\right) & \text { for } \dot{Q}^{* *} \leq 0.15 \\ 18.5 H \ln \left(\frac{0.43}{V^{* * *}}\right) & \text { for } \dot{Q}^{* *}>0.15\end{cases}
$$

with

$$
\begin{aligned}
\dot{Q}^{* *} & =\frac{Q-C_{P} \rho v S_{e} \Delta T_{\max } e^{\left(-\lambda D / C_{P} \dot{m}_{e}\right) d}}{\rho_{0} C_{P} T_{0} g^{1 / 2} H^{5 / 2}}, \\
V^{* * *} & =\frac{V+\rho v S_{e} / 2 A_{1} \rho_{0}}{\sqrt{g H}},
\end{aligned}
$$

where $v$ is the ceiling extraction velocity, $S_{e}$ is extraction opening area, $D$ is the part of the perimeter of the smoke flow cross section that contacts the channel surface, $d$ is the distance between heat source and the ceiling extraction opening, and $\lambda$ is a coefficient. The predictions by the proposed model were in good agreement with the experimental results. It should be mentioned that their study just included one ceiling opening. So, another practical scenario with multiextraction openings of different interval distance is needed to be investigated.

The maximum thermal smoke temperature and temperature decay were analyzed experimentally along the longitudinal centerline of the tunnel ceiling in Tang's study [43] with different horizontal gas fire source location to provide an improvement over former research. Three different locations, namely, Location A (close to the wall), Location B (near the wall), Location $C$ (centerline of the tunnel) were considered (Figure 12). 


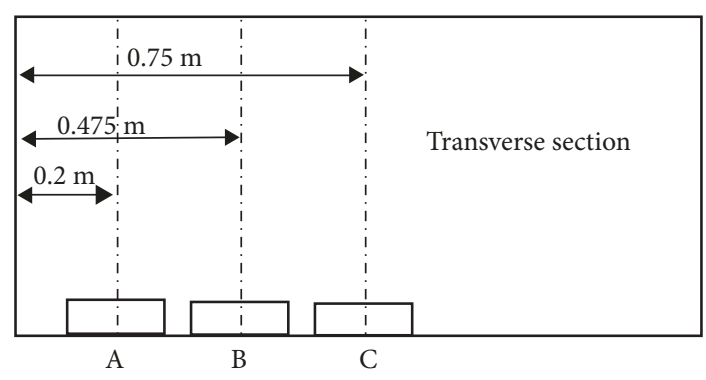

FIGURE 12: Three different fire source locations in [38, 43].

It is determined that the maximum smoke temperature beneath the ceiling with different transverse gas fire source locations was underestimated in the previous model ([40]). Major findings include the following:

(1) The transverse maximum smoke temperature was affected by the location of the gas burner and its distance to the side walls. When the fire source moved closer to the side wall, the transverse maximum thermal smoke temperature increased. However, it was the lowest for the centerline of the tunnel because of the enhancement of heat feedback from the sidewall of the tunnel to fire source.

(2) The modified model of maximum thermal smoke temperature below the ceiling of the tunnel with different horizontal gas burner location was defined as follows:

$$
\begin{aligned}
& \Delta T_{\max }^{\prime} \\
& \quad= \begin{cases}\left(1.37-\frac{0.37 l}{W / 2}\right) \frac{Q}{V r^{1 / 3} H_{d}^{5 / 3}} & \text { for } V^{\prime}>0.19 \\
17.5\left(1.33-\frac{0.33 l}{W / 2}\right) \frac{Q^{2 / 3}}{H_{d}^{5 / 3}} & \text { for } V^{\prime} \leq 0.19,\end{cases}
\end{aligned}
$$

where $\Delta T_{\max }^{\prime}$ is the maximum thermal smoke temperature beneath the ceiling in a tunnel with different horizontal gas burner (fire source) location and $l$ is the distance between the center line of the fire source and the tunnel sidewall. When the distance between the fire sources to the tunnel sidewall is larger, the thermal smoke temperature decays faster along the center line of the tunnel. The revised thermal smoke temperature decay formula along the center line of the tunnel is introduced as the following formula:

$$
\frac{\Delta T_{x}}{\Delta T_{0}}=\frac{T_{x}-T_{a}}{T_{0}-T_{a}}=e^{-(1.71-0.71 / / W / 2) K x} .
$$

$K$ was defined by (47).

The distance between the fire source and the downstream exit has a noticeable effect on the smoke flow characteristics due to the decreasing natural resistance between the fire and the ventilation flow when this distance becomes shorter. In addition to the influence of longitudinal fire source location, the distance between the fire source and sidewalls also should be considered. Although the impact of these two parameters has been studied by some researchers, this requires further research so that a general summary of the critical velocity, backlayering length, and the temperature stratification of smoke flow can be obtained in the situation where the source of fire is not located in the center.

\section{Conclusion}

Road tunnel fire safety concerns high uncertainty and highstake decisions. This overview shows that the critical velocity for longitudinal flow in tunnels and backlayering length are the most well investigated fire phenomena found in the tunnel fire research literature. Studies in the smoke movement systematically use scaled models. It is found that the critical velocity does vary as the one-third power of the heat release rate at low rates of heat release; however, at higher rates of heat release, the dependence of the critical velocity on the heat release rate decreases rapidly. Also, extensive works have been performed in the literature in characterizing the backlayering length in a longitudinal ventilated tunnel fire and the dependence of backlayering length on heat release rate, longitudinal ventilation velocity, tunnel geometry, and ambient characteristics. It can be concluded that backlayering length has a linear relation with HRR and in linear relation with ventilation velocity. Also, the influence of tunnel dimensions such as width, height, and height from the fire surface to the tunnel ceiling on backlayering length was examined in the literature. Although the smoke layering length for cases with the transverse exhausting system and point extraction were investigated, further study needs to obtain deep knowledge about this issue. Blockages influence local velocity near the fire source through the reduction of air entertainment. Based on this effect, the critical velocity decreases when an obstacle is located in a tunnel when ventilation velocity can reach the fire source. Moreover, the backlayering length becomes shorter in the existence of blockages. However, researchers considered the influence of slope and fire source location and analyzed the effects of them on the critical velocity and the backlayering characteristics, and our knowledge in some issues need to be investigated further, for example, flame length, the maximum smoke temperature, and temperature decay. Considerable work using model scale tunnels has added new information regarding tunnel fire and clarified many phenomena in this situation. However, the lack of largescale experimental data will be a key issue which should be considered in the near future.

\section{Nomenclature}

A: Cross-sectional area of tunnel, $\mathrm{m}^{2}$

$A_{2}$ : Cross-sectional area of the vehicular blockage, $\mathrm{m}^{2}$

$A_{S}:$ Aspect ratio

$C_{P}$ : Specific heat capacity, $\mathrm{kJkg}^{-1} \mathrm{~K}^{-1}$

$D$ : The part of the perimeter of the smoke flow cross section that contacts the channel surface, $m$

$d$ : The distance between the heat source and the ceiling extraction opening, $\mathrm{m}$ 


\begin{tabular}{|c|c|}
\hline Fr: & The Froude number \\
\hline$F r_{c}:$ & The critical Froude number \\
\hline$g:$ & Gravitational acceleration, $\mathrm{ms}^{-2}$ \\
\hline$H:$ & Tunnel height, $\mathrm{m}$ \\
\hline$h:$ & Lumped heat transfer coefficient, $\mathrm{kWm}^{-2} \mathrm{~K}^{-1}$ \\
\hline $\bar{H}:$ & Tunnel mean hydraulic diameter, $\mathrm{m}$ \\
\hline$H_{d}:$ & $\begin{array}{l}\text { Height from the fire surface to the tunnel } \\
\text { ceiling, } m\end{array}$ \\
\hline$H_{d T}:$ & $\begin{array}{l}\text { Height of boundary between thermal fumes } \\
\text { and fresh air, } \mathrm{m}\end{array}$ \\
\hline$H_{d T}^{*}:$ & $\begin{array}{l}\text { Dimensionless height of boundary of } \\
\text { thermal fumes, } \mathrm{H}_{d T} / \mathrm{H}\end{array}$ \\
\hline$L:$ & Fire source-vehicular blockage distance, $\mathrm{m}$ \\
\hline & $\begin{array}{l}\text { The distance between the centerline of the } \\
\text { gas burner and the tunnel sidewall, } \mathrm{m}\end{array}$ \\
\hline & Backlayering length, $\mathrm{m}$ \\
\hline & Dimensionless backlayering length \\
\hline$L_{T}^{o}:$ & Metro train length, $\mathrm{m}$ \\
\hline$L_{\text {blockage }}^{*}$ & $\begin{array}{l}\text { Dimensionless backlayering length with } \\
\text { blockage }\end{array}$ \\
\hline$L_{\text {blockage }(L)}^{*}$ : & $\begin{array}{l}\text { Dimensionless backlayering length with } \\
\text { different blockage-fire distance }\end{array}$ \\
\hline$\dot{m}_{a}:$ & $\begin{array}{l}\text { Total air mass flow rate inside the tunnel, } \\
\mathrm{kgs}^{-1}\end{array}$ \\
\hline$\dot{m}_{e}:$ & Mass flow rate of ceiling gas flow, $\mathrm{kgs}^{-1}$ \\
\hline$P:$ & Perimeter of the tunnel, $\mathrm{m}$ \\
\hline Q: & Heat release rate of the fire source, $\mathrm{kW}$ \\
\hline$Q^{\prime}:$ & $\begin{array}{l}\text { Fire convective heat release rate per tunnel } \\
\text { unit width, } \mathrm{kWm}^{-1}\end{array}$ \\
\hline$Q^{*}:$ & Dimensionless heat release rate \\
\hline Qexhaust: & $\begin{array}{l}\text { Part of heat exhausted from vertical shaft } \\
\text { [36], kW }\end{array}$ \\
\hline$Q_{\text {loss }}:$ & The heat of path loss [36], kW \\
\hline$Q_{u p}:$ & $\begin{array}{l}\text { The heat of smoke spreading upstream [36], } \\
\mathrm{kW}\end{array}$ \\
\hline$Q_{\text {virtual }}$ & $\begin{array}{l}\text { The virtual heat release rate of the virtual fire } \\
\text { source below the vertical shaft [36], } \mathrm{kW}\end{array}$ \\
\hline & Critical heat release rate in $(42), \mathrm{kW}$ \\
\hline$Q_{b-T}:$ & $\begin{array}{l}\text { Virtual fire source heat release rate at the rear } \\
\text { of metro train, } \mathrm{kW}\end{array}$ \\
\hline & Radius of the fire source, $\mathrm{m}$ \\
\hline Ri: & The Richardson number \\
\hline$R i_{c}:$ & The critical Richardson number \\
\hline$R i^{\prime}:$ & The modified Richardson number \\
\hline$S_{e}:$ & Cross-sectional area of vertical shaft, $\mathrm{m}^{2}$ \\
\hline$T:$ & Smoke temperature, $\mathrm{K}$ \\
\hline$T_{a}:$ & Ambient temperature, $\mathrm{K}$ \\
\hline$T_{0}^{a}:$ & Fire plume temperature at reference point, $\mathrm{K}$ \\
\hline$T_{x}:$ & Fire plume temperature at point $\mathrm{x}, \mathrm{K}$ \\
\hline$U_{c}:$ & Critical ventilation velocity, $\mathrm{ms}^{-1}$ \\
\hline$U_{C}^{*}:$ & Dimensionless critical velocity \\
\hline$U_{C, Y}:$ & $\begin{array}{l}\text { The critical ventilation velocity when the fire } \\
\text { is at the tunnel exit, } \mathrm{ms}^{-1}\end{array}$ \\
\hline$U_{\text {con }}$ & The confinement ventilation velocity, $\mathrm{ms}^{-1}$ \\
\hline & Longitudinal ventilation velocity, $\mathrm{ms}^{-1}$ \\
\hline & Dimensionless ventilation velocity \\
\hline & $\begin{array}{l}\text { The ratio of longitudinal ventilation velocity } \\
\text { to critical velocity }\end{array}$ \\
\hline
\end{tabular}

$V_{\text {blockage }}^{*} \quad$ Dimensionless critical velocity with blocks

$V_{\text {blockage }(L)}^{*}$ : Dimensionless critical velocity with different blockage-fire distance

$V_{C, \theta}: \quad$ The critical velocity of the inclined tunnel with slope, $\mathrm{ms}^{-1}$

W: $\quad$ Tunnel width, $\mathrm{m}$

$x_{r}: \quad$ Proportion of the radiation heat loss

$x_{f}: \quad$ Distance away from the fire source, $\mathrm{m}$

$Y: \quad$ The distance between the fire and tunnel exit, $m$

$\Delta T_{\max }: \quad$ Maximum excess gas temperature beneath the ceiling, $\mathrm{K}$

$\alpha: \quad$ Tunnel blockage ratio

$\lambda: \quad$ Heat transfer coefficient, $\mathrm{Wm}^{-2} \mathrm{~K}^{-1}$

$\theta: \quad$ The tunnel slope expressed in degrees

$\beta: \quad$ The ratio of tunnel width to tunnel height

$\varphi: \quad$ Percentage of the tunnel slope, \%

$\rho_{0}: \quad$ Ambient air density, $\mathrm{kgm}^{-3}$

$\rho_{d}: \quad$ Smoke density beneath vertical shaft, $\mathrm{kgm}^{-3}$

$\xi: \quad$ The sectional coefficient

$\omega: \quad$ Velocity of smoke into vertical shaft, $\mathrm{ms}^{-1}$

$v$ : $\quad$ Ceiling extraction velocity, $\mathrm{ms}^{-1}$.

\section{Conflicts of Interest}

The authors declare that they have no conflicts of interest.

\section{Acknowledgments}

We are very grateful to FRGS/1/2016/TK03/UKM/03/1 grant by the Ministry of Education, Malaysia (MoE).

\section{References}

[1] R. Khaksari, E. Reda, M. R. Rasani, C. M. Zedan, and Z. Harun, "Fire simulation of a scaled mass rapid transit (MRT) tunnel," Journal of Mechanical Engineering, vol. 1, no. 7, pp. 1-17, 2018.

[2] G. T. Atkinson and Y. Wu, "Smoke control in sloping tunnels," Fire Safety Journal, vol. 27, no. 4, pp. 335-341, 1996.

[3] L. F. Chen, L. H. Hu, X. L. Zhang, X. Z. Zhang, X. C. Zhang, and L. Z. Yang, "Thermal buoyant smoke back-layering flow length in a longitudinal ventilated tunnel with ceiling extraction at difference distance from heat source," Applied Thermal Engineering, vol. 78, pp. 129-135, 2015.

[4] W. K. Chow, K. Y. Wong, and W. Y. Chung, "Longitudinal ventilation for smoke control in a tilted tunnel by scale modeling," Tunnelling and Underground Space Technology, vol. 25, no. 2, pp. 122-128, 2010.

[5] N. Danziger, "Longtitudinal ventilation analysis for the glenwood canyon tunnels," in Proceedings of the 4th International Symposium on Aerodynamics \& Ventilation of Vehicle Tunnels, 1982.

[6] C. G. Fan, J. Ji, and J. H. Sun, "Influence of longitudinal fire location on smoke characteristics under the tunnel ceiling," Fire and Materials, vol. 39, no. 1, pp. 72-84, 2015.

[7] C. G. Fan and J. Yang, "Experimental study on thermal smoke backlayering length with an impinging flame under the tunnel ceiling," Experimental Thermal and Fluid Science, vol. 82, pp. 262-268, 2017. 
[8] A. Heselden, "Studies of fire and smoke behaviour relevant to tunnel," in Proceedings of the 2nd International Symposium on the Aerodynamics and Ventilation of Vehicle Tunnels, Cambridge, UK, March 1976.

[9] P. H. Thomas, "The movement of smoke in horizontal passages against an air flow," Fire Safety Science, vol. 723, p. 1, 1968.

[10] P. Hinkley, "The flow of hot gases along an enclosed shopping mall a tentative theory," Fire Safety Science, vol. 807, p. 1, 1970.

[11] Y. Oka and G. T. Atkinson, "Control of smoke flow in tunnel fires," Fire Safety Journal, vol. 25, no. 4, pp. 305-322, 1995.

[12] G. B. Grant, S. F. Jagger, and C. J. Lea, "Fires in tunnels," Philosophical Transactions of the Royal Society A: Mathematical, Physical \& Engineering Sciences, vol. 356, no. 1748, pp. 28732906, 1998.

[13] Y. Wu and M. Z. A. Bakar, "Control of smoke flow in tunnel fires using longitudinal ventilation systems - a study of the critical velocity," Fire Safety Journal, vol. 35, no. 4, pp. 363-390, 2000.

[14] S. R. Lee and H. S. Ryou, "An experimental study of the effect of the aspect ratio on the critical velocity in longitudinal ventilation tunnel fires," Journal of Fire Sciences, vol. 23, no. 2, pp. 119-138, 2005.

[15] J. P. Kunsch, "Simple model for control of fire gases in a ventilated tunnel," Fire Safety Journal, vol. 37, no. 1, pp. 67-81, 2002.

[16] O. Vauquelin and D. Telle, "Definition and experimental evaluation of the smoke "confinement velocity" in tunnel fires," Fire Safety Journal, vol. 40, no. 4, pp. 320-330, 2005.

[17] O. Vauquelin and Y. Wu, "Influence of tunnel width on longitudinal smoke control," Fire Safety Journal, vol. 41, no. 6, pp. 420426, 2006.

[18] O. Vauquelin, "Experimental simulations of fire-induced smoke control in tunnels using an "air-helium reduced scale model": principle, limitations, results and future," Tunnelling and Underground Space Technology, vol. 23, no. 2, pp. 171-178, 2008.

[19] J. S. Roh, S. S. Yang, and H. S. Ryou, “Tunnel fires: experiments on critical velocity and burning rate in pool fire during longitudinal ventilation," Journal of Fire Sciences, vol. 25, no. 2, pp. 161-176, 2007.

[20] Y. Z. Li, B. Lei, and H. Ingason, "Study of critical velocity and backlayering length in longitudinally ventilated tunnel fires," Fire Safety Journal, vol. 45, no. 6-8, pp. 361-370, 2010.

[21] Y. Z. Li and H. Ingason, "Effect of cross section on critical velocity in longitudinally ventilated tunnel fires," Fire Safety Journal, vol. 91, pp. 303-311, 2017.

[22] Y. Z. Li and H. Ingason, "Discussions on critical velocity and critical Froude number for smoke control in tunnels with longitudinal ventilation," Fire Safety Journal, vol. 99, pp. 22-26, 2018.

[23] Z. Harun, M. S. bin Sahari, and T. I. Mohamad, "Smoke simulation in an underground train station using computational fluid dynamic," Applied Mechanics and Materials, vol. 663, pp. 366372, 2014.

[24] P. Thomas, "The movement of buoyant fluid against a stream and the venting of underground fires," Fire Safety Science, vol. 351, p. 1, 1958.

[25] J. Vantelon, A. Guelzim, D. Quach, D. Son, D. Gabay, and D. Dallest, "Investigation of fire-induced smoke movement in tunnels and stations: an application to the paris metro," Fire Safety Science, vol. 3, pp. 907-918, 1991.

[26] T. Yamada, Y. Watanabe, S. Matsushima et al., "Ventilation criteria for preventing backing layer of smoke in case of tunnel fire," Report of National Research Institute of Fire and Disaster, vol. 1, no. 83, pp. 37-46, 1997.

[27] P. Deberteix, D. Gabay, and D. Blay, "Experimental study of fire-induced smoke propagation in a tunnel in the presence of longitudinal ventilation," in Proceedings of the International Conference on Tunnel Fires and Escape from Tunnels, pp. 257265, Washington, DC, USA, 2001.

[28] L. H. Hu, R. Huo, and W. K. Chow, "Studies on buoyancy-driven back-layering flow in tunnel fires," Experimental Thermal and Fluid Science, vol. 32, no. 8, pp. 1468-1483, 2008.

[29] K. Fujita, T. Minehiro, N. Kawabata, and F. Tanaka, "Temperature characteristics of backlayering thermal fumes in a tunnel fire," Journal of Fluid Science and Technology, vol. 7, no. 3, pp. 275-289, 2012.

[30] H. Ingason and Y. Z. Li, "Model scale tunnel fire tests with longitudinal ventilation," Fire Safety Journal, vol. 45, no. 6-8, pp. 371-384, 2010.

[31] A. Lonnermark and H. Ingason, "Ingason, Large scale fire tests in the Runehamar tunnel-Gas temperature and radiation," Tech. Rep., Sp Rapport-Statens Provningsanstalt, 2004.

[32] M. Boehm, L. Fournier, B. Truchot, and V.-e.-H. F. Ineris, Smoke stratification stability: presentation of experiments, na, 2007.

[33] J. S. Newman and A. Tewarson, "Flame propagation in ducts," Combustion and Flame, vol. 51, pp. 347-355, 1983.

[34] T. Minehiro, K. Fujita, N. Kawabata, M. Hasegawa, and F. Tanaka, "Backlayering distance of thermal fumes in tunnel fire experiments using a large-scale model," Journal of Fluid Science and Technology, vol. 7, no. 3, pp. 389-404, 2012.

[35] L. F. Chen, L. H. Hu, W. Tang, and L. Yi, "Studies on buoyancy driven two-directional smoke flow layering length with combination of point extraction and longitudinal ventilation in tunnel fires," Fire Safety Journal, vol. 59, pp. 94-101, 2013.

[36] Y. Yao, X. Cheng, S. Zhang, K. Zhu, L. Shi, and H. Zhang, "Smoke back-layering flow length in longitudinal ventilated tunnel fires with vertical shaft in the upstream," Applied Thermal Engineering, vol. 107, pp. 738-746, 2016.

[37] Y.-P. Lee and K.-C. Tsai, "Effect of vehicular blockage on critical ventilation velocity and tunnel fire behavior in longitudinally ventilated tunnels," Fire Safety Journal, vol. 53, pp. 35-42, 2012.

[38] W. Tang, L. H. Hu, and L. F. Chen, "Effect of blockage-fire distance on buoyancy driven back-layering length and critical velocity in a tunnel: an experimental investigation and global correlations," Applied Thermal Engineering, vol. 60, no. 1-2, pp. 7-14, 2013.

[39] L. H. Hu, W. Tang, L. F. Chen, and L. Yi, "A non-dimensional global correlation of maximum gas temperature beneath ceiling with different blockage-fire distance in a longitudinal ventilated tunnel," Applied Thermal Engineering, vol. 56, no. 1-2, pp. 77-82, 2013.

[40] Y. Z. Li, B. Lei, and H. Ingason, "The maximum temperature of buoyancy-driven smoke flow beneath the ceiling in tunnel fires," Fire Safety Journal, vol. 46, no. 4, pp. 204-210, 2011.

[41] A. Kashef, Z. Yuan, and B. Lei, "Ceiling temperature distribution and smoke diffusion in tunnel fires with natural ventilation," Fire Safety Journal, vol. 62, no. C, pp. 249-255, 2013.

[42] S. Zhang, X. Cheng, Y. Yao et al., "An experimental investigation on blockage effect of metro train on the smoke back-layering in subway tunnel fires," Applied Thermal Engineering, vol. 99, pp. 214-223, 2016.

[43] F. Tang, L. Li, W. Chen, C. Tao, and Z. Zhan, "Studies on ceiling maximum thermal smoke temperature and longitudinal decay 
in a tunnel fire with different transverse gas burner locations," Applied Thermal Engineering, vol. 110, pp. 1674-1681, 2017.

[44] W. U. Rojas Alva, G. Jomaas, and A. S. Dederichs, "Scaled experiments using the helium technique to study the vehicular blockage effect on longitudinal ventilation control in tunnels," in Proceedings of the 16th International Symposium on Aerodynamics, Ventilation and Fire in Tunnels (ISAVFT '15), pp. 49-64, Seattle, Wash, USA, September 2015.

[45] W. U. Rojas Alva, G. Jomaas, and A. S. Dederichs, "The influence of vehicular obstacles on longitudinal ventilation control in tunnel fires," Fire Safety Journal, vol. 87, pp. 25-36, 2017.

[46] Y. Wu, G. Atkinson, J. Stoddard, and P. James, "Effect Of slope on control of smoke flow in tunnel fires," Fire Safety Science, vol. 5, pp. 1225-1236, 1997.

[47] O. Vauquelin, "Parametrical study of the back flow occurrence in case of a buoyant release into a rectangular channel," Experimental Thermal and Fluid Science, vol. 29, no. 6, pp. 725731, 2005.

[48] G. H. Ko, S. R. Kim, and H. S. Ryou, "An experimental study on the effect of slope on the critical velocity in tunnel fires," Journal of Fire Sciences, vol. 28, no. 1, pp. 27-47, 2010.

[49] L. H. Hu, L. F. Chen, L. Wu, Y. F. Li, J. Y. Zhang, and N. Meng, "An experimental investigation and correlation on buoyant gas temperature below ceiling in a slopping tunnel fire," Applied Thermal Engineering, vol. 51, no. 1-2, pp. 246-254, 2013.

[50] L. H. Hu, R. Huo, H. B. Wang, Y. Z. Li, and R. X. Yang, "Experimental studies on fire-induced buoyant smoke temperature distribution along tunnel ceiling," Building and Environment, vol. 42, no. 11, pp. 3905-3915, 2007.

[51] L. H. Hu, R. Huo, W. K. Chow, H. B. Wang, and R. X. Yang, "Decay of buoyant smoke layer temperature along the longitudinal direction in tunnel fires," Journal of Applied Fire Science, vol. 13, no. 1, pp. 53-77, 2004.

[52] M.-C. Weng, X.-L. Lu, F. Liu, and C.-X. Du, "Study on the critical velocity in a sloping tunnel fire under longitudinal ventilation," Applied Thermal Engineering, vol. 94, pp. 422-434, 2016.

[53] L.-X. Yu, F. Liu, Y.-Q. Liu, M.-C. Weng, and S.-J. Liao, "Experimental study on thermal and smoke control using transverse ventilation in a sloping urban traffic link tunnel fire," Tunnelling and Underground Space Technology, vol. 71, pp. 81-93, 2018.

[54] K.-C. Tsai, H.-H. Chen, and S.-K. Lee, "Critical ventilation velocity for multi-source tunnel fires," Journal of Wind Engineering \& Industrial Aerodynamics, vol. 98, no. 10-11, pp. 650-660, 2010.

[55] K.-C. Tsai, Y.-P. Lee, and S.-K. Lee, "Critical ventilation velocity for tunnel fires occurring near tunnel exits," Fire Safety Journal, vol. 46, no. 8, pp. 556-557, 2011.

[56] L. H. Hu, W. Peng, and R. Huo, "Critical wind velocity for arresting upwind gas and smoke dispersion induced by nearwall fire in a road tunnel," Journal of Hazardous Materials, vol. 150, no. 1, pp. 68-75, 2008. 


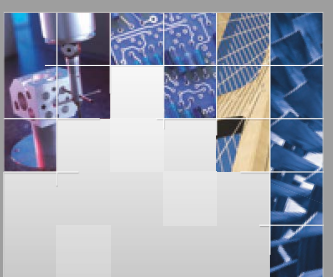

\section{Enfincering}
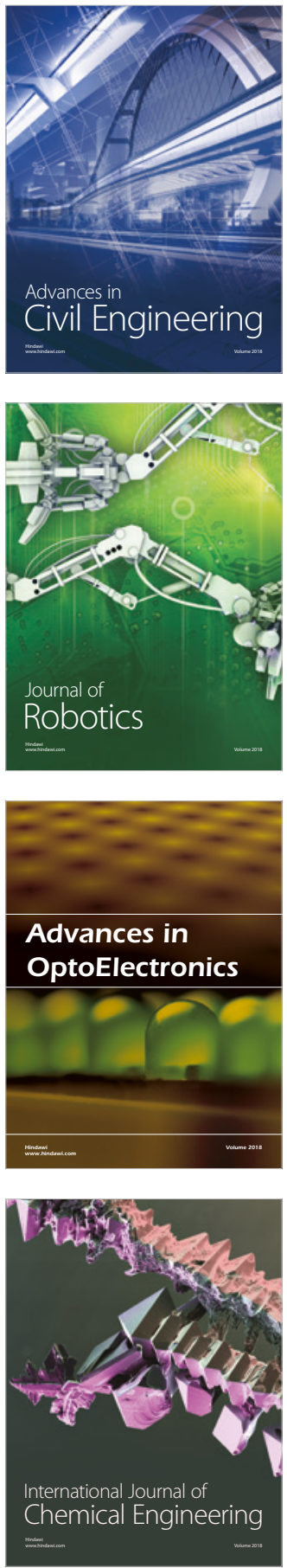

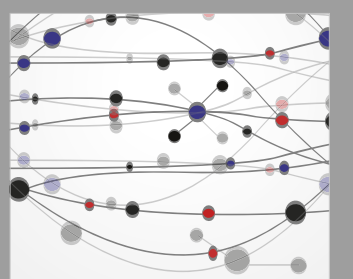

\section{Rotating \\ Machinery}

The Scientific World Journal

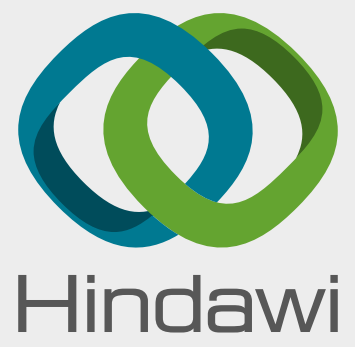

Submit your manuscripts at

www.hindawi.com
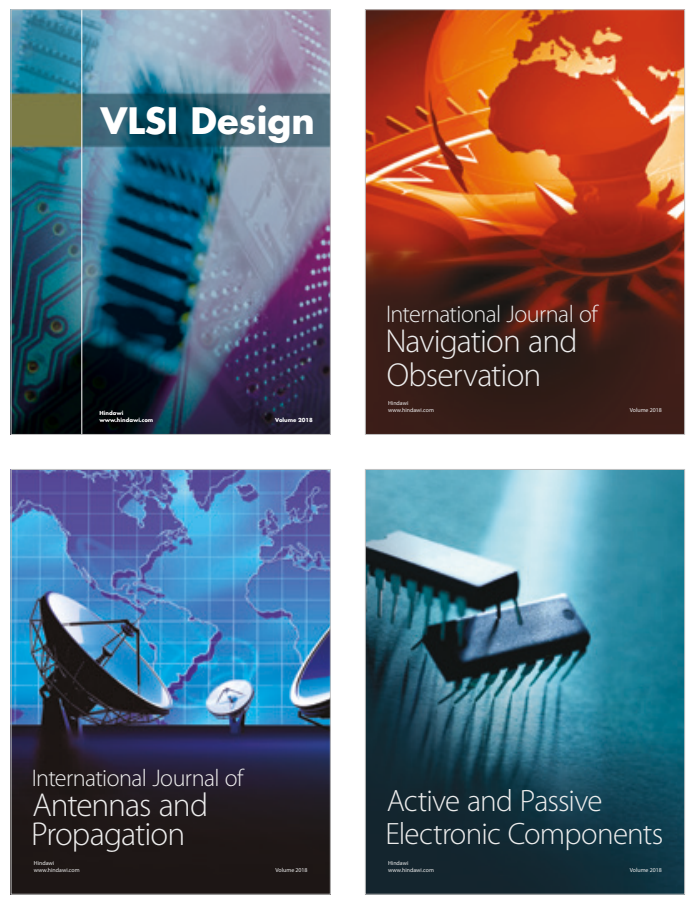
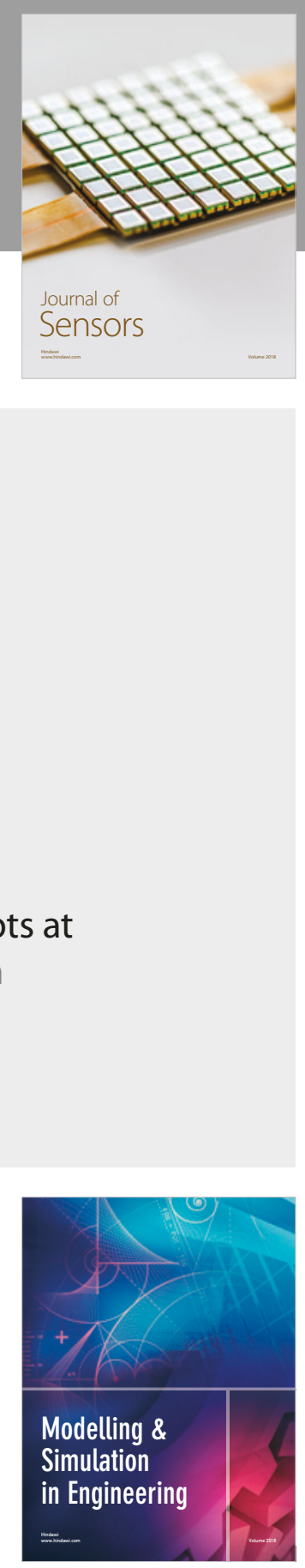

\section{Advances \\ Multimedia}
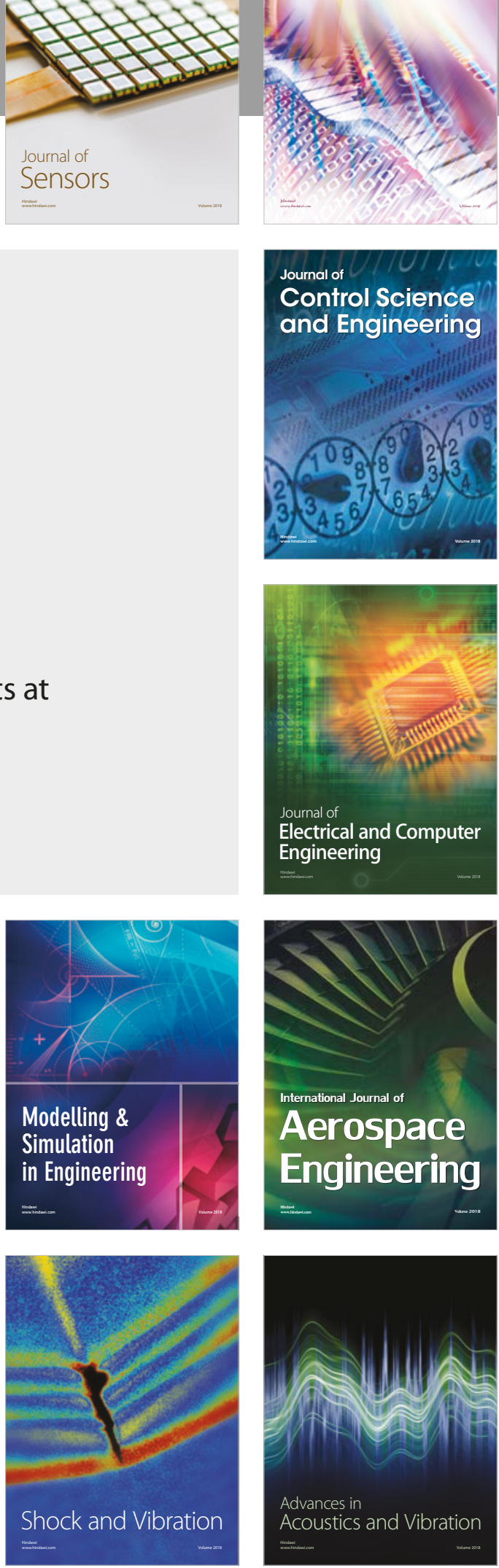